\title{
Blood coagulation factor XII drives adaptive immunity during neuroinflammation via CD87-mediated modulation of dendritic cells
}

Kerstin Göbel ${ }^{1}$, Susann Pankratz ${ }^{1, \star}$, Chloi-Magdalini Asaridou ${ }^{1}$, Alexander M. Herrmann ${ }^{1}$, Stefan Bittner ${ }^{1,2}$, Monika Merker ${ }^{1}$, Tobias Ruck ${ }^{1}$, Sarah Glumm , Friederike Langhauser ${ }^{3}$, Peter Kraft ${ }^{3}$, Thorsten F. Krug ${ }^{1}$, Johanna Breuer ${ }^{1}$, Martin Herold', Catharina C. Gross', Denise Beckmann ${ }^{4}$, Adelheid Korb-Pap ${ }^{4}$, Michael K. Schuhmann ${ }^{3}$, Stefanie Kuerten ${ }^{5}$, loannis Mitroulis ${ }^{6}$, Clemens Ruppert ${ }^{7}$, Marc W. Nolte ${ }^{8}$, Con Panousis ${ }^{9}$, Luisa Klotz ${ }^{1}$, Beate Kehrel ${ }^{10}$, Thomas Korn ${ }^{11}$, Harald F. Langer ${ }^{12}$, Thomas Pap ${ }^{4}$, Bernhard Nieswandt ${ }^{13}$, Heinz Wiendl ${ }^{1}$, Triantafyllos Chavakis ${ }^{6}$, Christoph Kleinschnitz $^{3,14, \star}$ \& Sven G. Meuth ${ }^{1}$

\begin{abstract}
Aberrant immune responses represent the underlying cause of central nervous system (CNS) autoimmunity, including multiple sclerosis (MS). Recent evidence implicated the crosstalk between coagulation and immunity in CNS autoimmunity. Here we identify coagulation factor XII (FXII), the initiator of the intrinsic coagulation cascade and the kallikrein-kinin system, as a specific immune cell modulator. High levels of FXII activity are present in the plasma of MS patients during relapse. Deficiency or pharmacologic blockade of FXII renders mice less susceptible to experimental autoimmune encephalomyelitis (a model of MS) and is accompanied by reduced numbers of interleukin-17A-producing T cells. Immune activation by FXII is mediated by dendritic cells in a CD87-dependent manner and involves alterations in intracellular cyclic AMP formation. Our study demonstrates that a member of the plasmatic coagulation cascade is a key mediator of autoimmunity. FXII inhibition may provide a strategy to combat MS and other immune-related disorders.
\end{abstract}

\footnotetext{
${ }^{1}$ Department of Neurology, Clinic of Neurology and Institute for Translational Neurology, University of Münster, 48149 Münster, Germany. ${ }^{2}$ Department of Neurology, University Medical Center of the Johannes Gutenberg-University, 55131 Mainz, Germany. ${ }^{3}$ Department of Neurology, University Hospital Würzburg, 97080 Würzburg, Germany. ${ }^{4}$ Institute of Experimental Musculoskeletal Medicine, University Hospital Münster, 48149 Münster, Germany. ${ }^{5}$ Department of Anatomy and Cell Biology, University of Würzburg, 97070 Würzburg, Germany. ${ }^{6}$ Department of Clinical Pathobiochemistry and Institute for Clinical Chemistry and Laboratory Medicine, University Clinic Carl Gustav Carus, Technische Universität of Dresden, 01307 Dresden, Germany. ${ }^{7}$ Department of Internal Medicine, Universities of Giessen \& Marburg Lung Center (UGMLC)/Member of the German Center for Lung Research (DZL), Justus-Liebig University, 35392 Giessen, Germany. ${ }^{8}$ CSL Behring GmbH, 35041 Marburg, Germany. ${ }^{9}$ CSL Limited, Bio21 Institute, Parkville, Victoria 3010, Australia. 10 Department of Anesthesiology, Intensive Care and Pain Medicine, Experimental and Clinical Hemostasis, University of Münster, 48149 Münster, Germany. ${ }^{11}$ Department of Neurology, Klinikum rechts der Isar, Technical University of Munich, 81675 Munich, Germany. ${ }^{12}$ Department of Cardiology and Cardiovascular Medicine, Section for Cardioimmunology, University Clinic of Tübingen, 72076 Tübingen, Germany. ${ }^{13}$ Rudolf Virchow Center, Deutsche Forschungsgemeinschaft Research Center for Experimental Biomedicine, University of Würzburg, 97080 Würzburg, Germany. ${ }^{14}$ Department of Neurology, University Hospital Essen, 45147 Essen, Germany. ${ }^{*}$ These authors contributed equally to this work. Correspondence and requests for materials should be addressed to K.G. (email: kerstin.goebel@ukmuenster.de) or S.G.M (email: sven.meuth@ukmuenster.de).
} 
A utoimmune diseases of the central nervous system (CNS), such as multiple sclerosis (MS), are mediated by the intimate interplay of many cellular and molecular immune components ${ }^{1,2}$. It is widely accepted that autoreactive $\mathrm{T}$ cells generated in the periphery migrate across the blood-brain barrier (BBB), inducing disseminated inflammatory lesions within the brain parenchyma, leading to demyelination. Recent studies suggest that both interferon (IFN)- $\gamma$ - and interleukin (IL)-17A-producing effector T-helper cells $\left(\mathrm{T}_{\mathrm{H}} 1\right.$ and $\mathrm{T}_{\mathrm{H}} 17$, respectively) contribute to inflammation and tissue damage in the course of CNS autoimmunity ${ }^{3-5}$. Interaction of $\mathrm{T}$ cells with dendritic cells (DCs), professional antigen-presenting cells (APCs), is crucial for T-cell differentiation ${ }^{6,7}$. Accumulation of effector $\mathrm{T}$ cells in human brain lesions and subsequent increased expression of cell-specific signature cytokines in peripheral blood mononuclear cells (PBMCs) of patients also indicate a role of autoreactive $\mathrm{T}$ cells in human $\mathrm{MS}^{8,9}$.

More recent evidence suggests that other factors not traditionally considered components of the immune system might also be involved in MS pathophysiology. In particular, blood coagulation constituents, such as platelets, are thought to contribute to experimental autoimmune encephalomyelitis (EAE), the mouse model of human $\mathrm{MS}^{10}$. Moreover, deposition of plasmatic coagulation factors, such as fibrinogen, has been described in human MS lesions ${ }^{11-13}$, and tissue factor and protein $\mathrm{C}$ inhibitor have been identified within chronic active MS plaques ${ }^{14}$.

Although findings indicate a role of the extrinsic coagulation system in EAE and MS, the function of the intrinsic coagulation system remains unknown. The initiator of intrinsic coagulation is factor XII (FXII; Hageman factor) ${ }^{15}$. FXII activation occurs through the contact with negatively charged surfaces ${ }^{16}$, resulting in activation of the intrinsic blood coagulation system and subsequently fibrin clot formation ${ }^{15,17}$. FXII also triggers the proinflammatory kallikrein-kinin system (KKS), which consists of several sequentially linked serine proteases, with the peptide hormone bradykinin (BK) being the end product. In addition, FXII may interact with cell-surface-associated receptors, such as the urokinase plasminogen activator receptor (also designated CD87) ${ }^{18}$.

As FXII is at the interface between inflammation and coagulation, and has recently been identified as a major driving force during ischaemic neurodegeneration ${ }^{19}$, we therefore investigated its role in autoimmunity and the potential underlying mechanisms of action. Moreover, we assessed FXII as a therapeutic target in different EAE models. We showed that FXII drives pathologic adaptive immune reactions via CD87-mediated modulation of DC.

\section{Results}

FXII-deficient mice are less susceptible to CNS inflammation. To assess whether FXII is relevant during CNS autoimmunity in vivo, we first analysed the plasma, lymph nodes (LNs) and the inflamed CNS of myelin oligodendrocyte glycoprotein 35-55 $\left(\mathrm{MOG}_{35-55}\right)$-immunized wild-type (WT) mice. Interestingly, FXII levels were significantly increased in the plasma and LN on disease maximum of EAE (Fig. 1a). Despite these peripheral alterations, extensive FXII depositions could also be found in the inflamed CNS of immunized mice (Fig. 1a,b), implying a potential contribution of FXII to EAE pathology.

To this end, we subjected FXII-deficient $\left(F 12^{-/-}\right)$mice to EAE. $F 12^{-1-}$ and WT control mice were immunized with $\mathrm{MOG}_{35-55}$, and clinical scores were evaluated daily over a 35-day period. FXII deficiency was associated with later disease onset and reduced maximum disease severity $\left(d_{\max }\right)$ (Fig. 1c; Supplementary Table 1). Inflammatory infiltrates and demyelination were less prevalent in $\mathrm{MOG}_{35-55^{-}}$-immunized $F 12^{-/-}$mice compared with
WT mice (Fig. 1d). While the distribution of different immune cell subsets in spleens and LNs from $F 12^{-/-}$and WT mice was only slightly shifted under basal (that is, non-immunized, reduced $\mathrm{CD}_{11 \mathrm{c}^{+}}$cells, increased forkhead box P3 (FoxP3) cells) and $\mathrm{MOG}_{35-55}$-immunized conditions (Supplementary Table 2; Supplementary Fig. 1), FXII deficiency was associated with lower relative numbers of $\mathrm{CD}^{+}{ }^{+}$and $\mathrm{CD} 8^{+} \mathrm{T}$ cells as well as $\mathrm{CD} 11 \mathrm{~b}^{+}$ and $\mathrm{CD}_{11 \mathrm{c}^{+}}$cells in the CNS of EAE mice at $d_{\max }$ (Supplementary Table 2; Supplementary Fig. 2).

Importantly, reconstitution of $F 12^{-/-}$animals with human FXII fully restored the susceptibility to EAE (Fig. 1e), indicating that the protective phenotype in EAE, due to FXII deficiency, can be specifically attributed to the absence of FXII. To further test whether FXII is involved in the priming or effector phase of EAE, we performed adoptive transfer (AT)-EAE. Interestingly, WT and $F 12^{-/-}$animals that received $F 12^{-/-}$LN cells developed almost no signs of EAE. Similarly, $F 12^{-/-}$mice receiving LN cells from WT or $\mathrm{F} 12^{-I-}$ mice were likewise protected from AT-EAE, indicating that FXII impacts priming as well as the effector mechanisms within the inflamed CNS (Fig. 1f).

FXII shifts immune cells towards a $\mathbf{T}_{\mathbf{H}} \mathbf{1 7}$ pattern. We next evaluated the differentiation of immune cells on $\mathrm{MOG}_{35-55}$ immunization in an FXII-deficient or -proficient setting. To this end, active EAE was induced in WT and $F 12^{-/-}$animals. At day 10 (priming phase) and $d_{\max }$ (day 16) of EAE, the amount of several transcription factor genes was determined in $\mathrm{CD}_{4}^{+}$ $\mathrm{T}$ cells obtained from the LN or CNS infiltrates by real-time reverse transcription-PCR (rRT-PCR). CD4 ${ }^{+} \mathrm{T}$ cells of $\mathrm{F} 12^{-/-}$ animals displayed no significant difference in $T b \times 21$ (coding for Tbet; a $\mathrm{T}_{\mathrm{H}} 1$ marker) and in Gata3 transcripts (a $\mathrm{T}_{\mathrm{H}} 2$ marker), but a significant decrease in retinoic acid receptor-related orphan receptor $\mathrm{C}$ (Rorc) transcripts (encoding the $\mathrm{T}_{\mathrm{H}} 17$ specification marker) and an increase in Foxp3 transcripts (a marker of regulatory $\mathrm{T}$ cells $\left(\mathrm{T}_{\text {reg }}\right)$ ) at day 10 (Fig. 2a). No significant changes were observed for any of these transcripts in $\mathrm{CD} 4{ }^{+} \mathrm{T}$ cells at $d_{\max }$ (Fig. 2a). In line with the findings in the preclinical phase of EAE, brain-infiltrating lymphocytes (BILs) of $F 12^{-/-}$ animals displayed a similar pattern of Tbx21, Gata3, Rorc and Foxp3 transcripts at $d_{\max }$, as already shown for CD $4^{+} \mathrm{T}$ cells at day 10 (Fig. 2a). These data suggest a FXII-induced shift to a $\mathrm{T}_{\mathrm{H}} 17$ signature in response to $\mathrm{MOG}_{35-55}$ immunization.

While proliferation of $\mathrm{CD} 4^{+} \mathrm{T}$ cells was unchanged in $\mathrm{F} 12^{-/-}$ mice compared with WT animals, FXII favoured $\mathrm{T}_{\mathrm{H}} 17$ cell emergence as indicated by the cytokine profile (low IL-17A, unaltered IFN- $\gamma$, IL-10 and transforming growth factor (TGF)- $\beta$ from CD4 ${ }^{+} \mathrm{T}$ cells within LN, and low IL-6, IL-23, unaltered IL-10, IL-12, IL-27 and TGF- $\beta$ from CD11c ${ }^{+}$DC; Fig. $\left.2 b\right)$ and by the number of IL-17A-producing $\mathrm{CD} 4{ }^{+} \mathrm{T}$ cells obtained from LNs, as determined by flow cytometry in the preclinical phase (day 10; Fig. 2c). The same signature could be found in the CNS of EAE mice on $d_{\max }$ (low IL-6, IL-17A, IL-23, increased IL-27, unaltered IFN- $\gamma$, IL-10, IL-12, TGF- $\beta$ and increased number of IL-17A-producing lymphocytes, Fig. 2d,e), while peripheral changes were already lost (unaltered number of IL-17Aproducing cells, Fig. 2f). Notably, the amount of IL-17Aproducing $\mathrm{MOG}_{35-55}$-activated $\mathrm{CD}^{+}{ }^{+} \mathrm{CD} 40$ ligand $(\mathrm{CD} 40 \mathrm{~L})^{+}$ $\mathrm{T}$ cells obtained from draining $\mathrm{LN}$ was reduced in $\mathrm{F} 12^{-/-}$mice, as compared with WT animals, while the number of IFN- $\gamma$ producing $\mathrm{CD}^{+}{ }^{+} \mathrm{CD} 40 \mathrm{~L}^{+} \mathrm{T}$ cells was unaltered, suggesting that antigen-specific sensitization and priming of $\mathrm{T}_{\mathrm{H}} 17$ cells is impaired in FXII deficiency (Supplementary Fig. 3).

FXII worsens EAE independently of the coagulation and KKS. FXII can initiate both the proinflammatory KKS, resulting in BK 

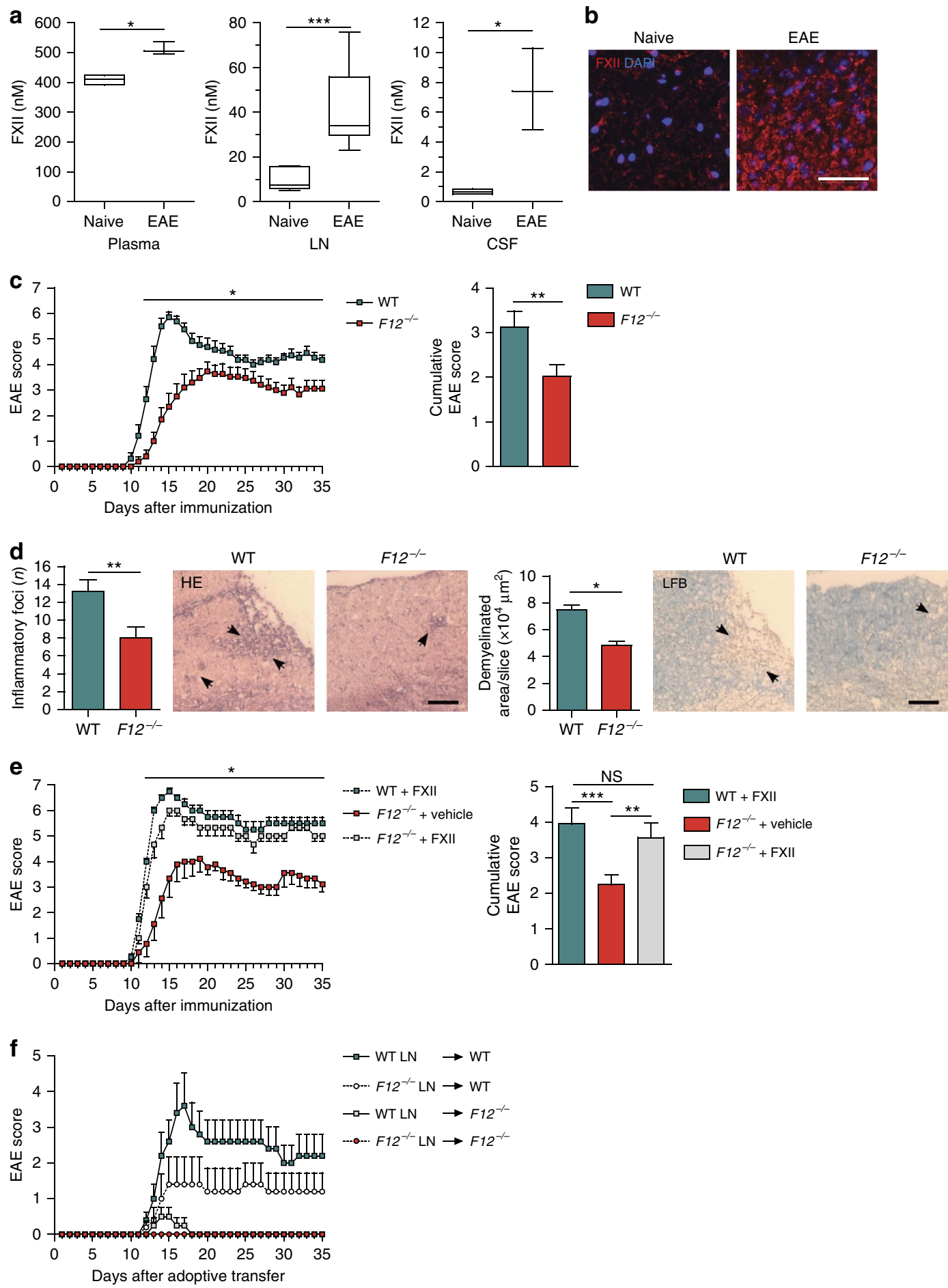

Figure 1 | FXII-deficient animals are less susceptible to neuroinflammation. (a) FXII levels in plasma, LN and CSF of naive and active EAE-induced WT animals at $d_{\max }$ (day 16) were analysed by ELISA. Data are given as mean \pm s.e.m. from three independent experiments, each with five animals per group (Student's $t$-test). (b) Histological analysis of spinal cord sections from the lumbar region of MOG $_{35-55}$-immunized WT animals at $d_{\text {max }}$ is shown. Sections were stained for FXII (red) and nucleus (4,6-diamidino-2-phenylindole (DAPI), blue). Scale bar, $50 \mu \mathrm{m}$. (c) Active EAE was induced in WT and F12- /- mice. Data are mean clinical scores \pm s.e.m. and mean cumulative scores \pm s.e.m. of WT and $F 12^{-/}$- animals from three independent experiments (non-parametric Mann-Whitney U-test). For detailed animal numbers and additional information, see Supplementary Table 1. (d) Identification of inflammatory foci (left panels) and demyelination (right panels) in spinal cord sections from the lumbar region of WT and $F 12^{-/-}$animals by haematoxylin and eosin (HE) or Luxol fast blue (LFB) staining. Scale bars, $100 \mu \mathrm{m}$. Quantification and representative histological sections from $d_{\max }$ of EAE are shown. Data are presented as mean \pm s.e.m. ( $n=3$ slices of six mice per group, Student's $t$-test). Arrows indicate inflammation or demyelinated areas, respectively. (e) Mean clinical scores and mean cumulative scores \pm s.e.m. over time of WT or $F 12^{-/}$- mice treated daily with intravenous injections of FXII (200 mg kg ${ }^{-1}$ body weight) or corresponding vehicle since $\mathrm{MOG}_{35-55}$ immunization are shown. (f) $E A E$ development in $W T$ and $F 12^{-/-}$mice after adoptive transfer of encephalitogenic $L N$ cells is shown. LN cells were isolated from WT or $F 12^{-/-}$mice on day 12 post immunization and restimulated in vitro with $10 \mu \mathrm{g} \mathrm{ml} \mathrm{m}^{-1} \mathrm{MOG}_{35-55}$ and $0.5 \mathrm{ng} \mathrm{ml}^{-1}$ interleukin-12. After $72 \mathrm{~h}, 8.4 \times 10^{6} \mathrm{LN}$ cells were either transferred into WTor $F 12^{-/-}$recipient mice. Mean clinical scores $\pm \mathrm{s}$.e.m. over time of three independent experiments are given (non-parametric Mann-Whitney U-test). ${ }^{\star} P<0.05,{ }^{\star \star} P<0.01,{ }^{\star \star \star} P<0.001$; NS, not significant. 
a

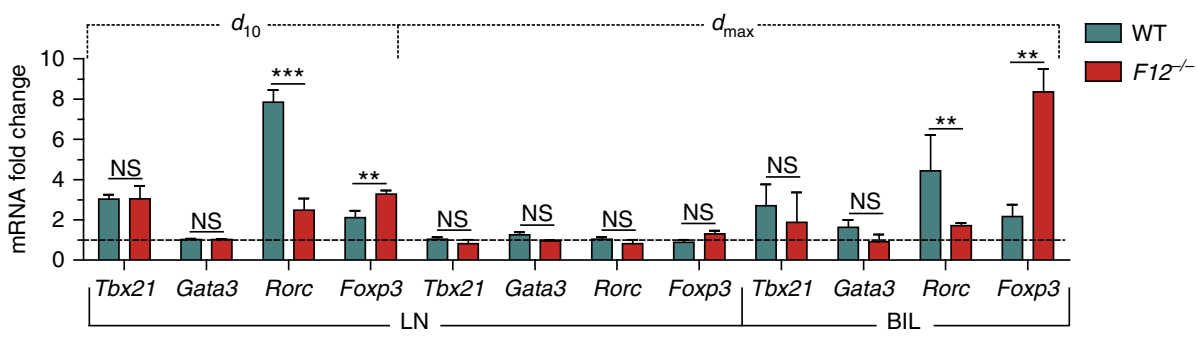

$\mathbf{b}_{\mathrm{LN} d_{10}}$
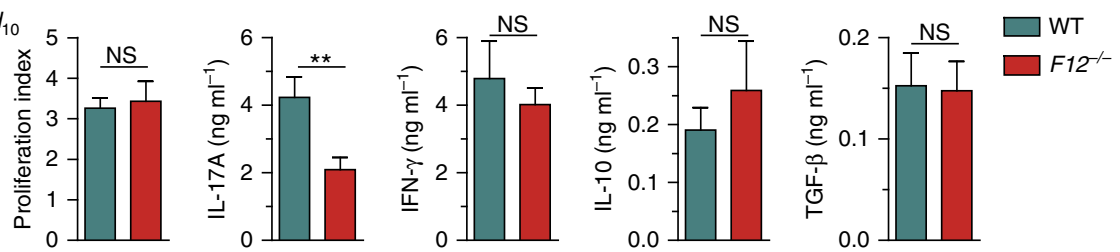

$\mathrm{CD} 11 \mathrm{c}^{+} \mathrm{DC} d_{10}$
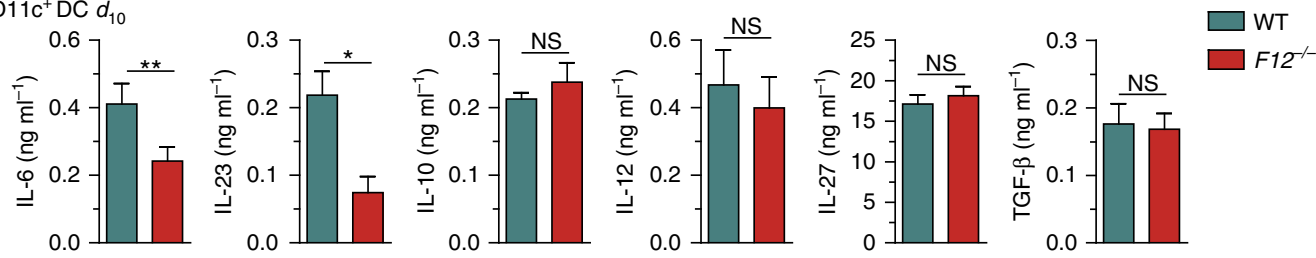

C
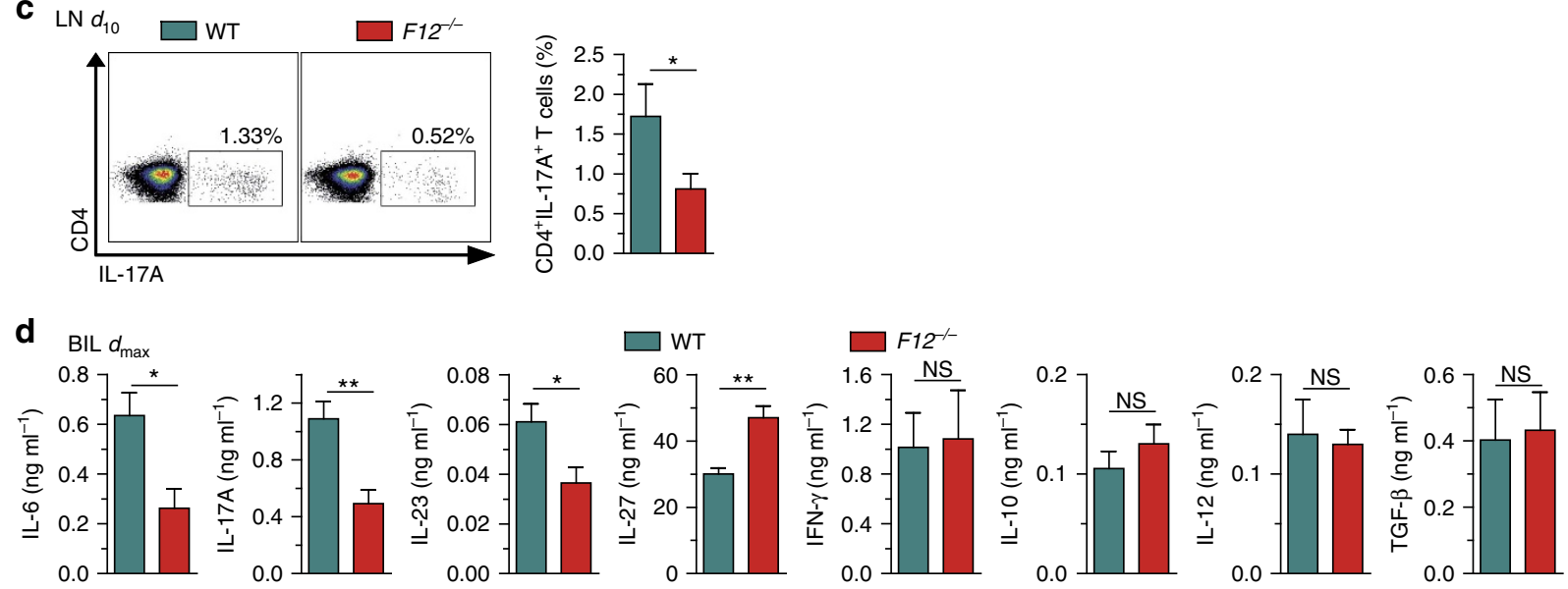

e BIL $d_{\max }$
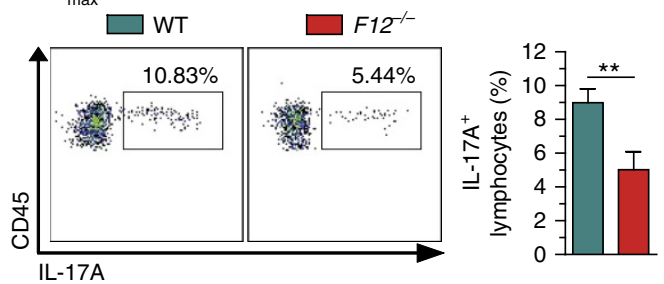

$\mathbf{f}_{\mathrm{LN} d_{\max }}$
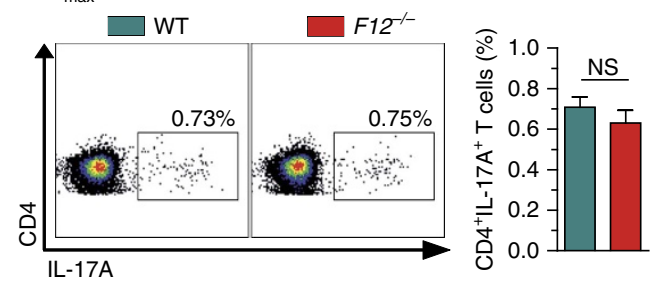

Figure 2 | Factor XII deficiency alters T-cell differentiation. (a) Tbx21, Gata3, Rorc and Foxp3 expression from LN cells at day 10 ( $d_{10}$ ) or $d_{\text {max }}$ as well as from brain-infiltrating leukocytes (BILs) at $d_{\max }$ after $\mathrm{MOG}_{35-55}$ immunization is determined by real-time reverse transcription-PCR using $18 \mathrm{~S}$ rRNA for normalization. Data (mean \pm s.e.m. of five experiments) are given as fold change in normalized gene expression in animals relative to WT controls. (b) At $d_{10}$ after $\mathrm{MOG}_{35-55}$ immunization, proliferation and cytokine production by $\mathrm{CD}_{4}{ }^{+} \mathrm{T}$ cells purified from $\mathrm{LN}$ and restimulated with $10 \mu \mathrm{g} \mathrm{ml}{ }^{-1} \mathrm{MOG}_{35-55}$ and irradiated ( $35 \mathrm{~Gy}$ ) antigen-presenting cells in vitro for $48 \mathrm{~h}$ (upper panels), and by CD11c ${ }^{+}$DCs purified from spleens and incubated with $1 \mu \mathrm{g} \mathrm{ml}{ }^{-1} \mathrm{LPS}$ in vitro for $48 \mathrm{~h}$ (lower panels) are shown. (c) Mononuclear cells were isolated from the LN of WT and $F 12^{-/}-$animals at $d_{10}$ post induction of EAE. Cells were polyclonal restimulated in vitro, stained with anti-CD3 and anti-CD4, fixed and permeabilized, stained intracellularly with anti-IL-17A and analysed by flow cytometry for the percentage of IL-17A-producing CD4 ${ }^{+}$T cells. (d) Cytokine production by purified BILs from MOG $35-55^{-i m m u n i z e d ~ W T ~ o r ~ F 12-/ ~}-$ mice at $d_{\max }$ after restimulation with $10 \mu \mathrm{g} \mathrm{ml}{ }^{-1} \mathrm{MOG}_{35-55}$ for $48 \mathrm{~h}$. (e,f) BILs and LNs were isolated from WT and F12- ${ }^{-}-$animals at $d_{\text {max }}$ post induction of EAE and polyclonal restimulated in vitro. For the detection of the percentage of IL-17A-producing lymphocytes (CD45 high $C D 11 b^{\text {neg }}$ cells or CD4 ${ }^{+}$CD3 ${ }^{+} \mathrm{T}$ cells), BILs or LNs were stained with anti-CD11b and anti-CD45, or anti-CD3 and anti-CD4, fixed and permeabilized, stained intracellularly with anti-IL-17A and analysed by flow cytometry. In $\mathbf{b}-\mathbf{f}$, data are given as means \pm s.e.m. of three independent experiments, each performed in triplicate. For $\mathbf{c}, \mathbf{e}$ and $\mathbf{f}$, representative dot plots for IL-17A expression are shown. For a-f, non-parametric Mann-Whitney U-test. ${ }^{\star} P<0.05,{ }^{\star \star} P<0.01,{ }^{\star \star \star} P<0.001$; NS, not significant. 
release, and the intrinsic coagulation cascade, leading to fibrin formation ${ }^{20}$. Although basal serum BK levels were lower when FXII was absent, cerebrospinal fluid (CSF) BK levels of immunized $F 12^{-l-}$ animals were indistinguishable from those of immunized WT mice (Supplementary Fig. 4a). Accordingly, $\mathrm{BK}$ receptor $1(\mathrm{~B} 1 \mathrm{R})$ or $\mathrm{B} 2 \mathrm{R}$ expression levels in the inflamed spinal cords from $F 12^{-1-}$ and WT mice did not differ on EAE induction (Supplementary Fig. 4b). We recently showed that blockade of B1R on endothelial cells reduces immune cell invasion across the activated $\mathrm{BBB}$ in $\mathrm{EAE}^{21}$. We therefore analysed the impact of FXII deficiency on the migratory capacity of LN-derived immune cells in an in vitro transmigration assay, using murine brain microvascular endothelial cells (MBMECs) from B1R-deficient or WT mice. The number of immune cells crossing the MBMEC barrier did not differ significantly in either group (Supplementary Fig. 4c).

Western blot analysis revealed that the amount of fibrin/ fibrinogen detectable in the CNS was similar between WT and $F 12^{-l-}$ mice at $d_{\max }$ (Supplementary Fig. $4 \mathrm{~d}$ ). That the effects of FXII in EAE were not mediated by the intrinsic coagulation system was corroborated by the fact that deficiency of FXI, the primary substrate of activated FXII during thrombus formation, did not alter the clinical course, demyelination, immune cell infiltration or cytokine levels in the course of EAE (Supplementary Fig. 4e-g). Overall, these findings indicate that the detrimental effects of FXII in autoimmune CNS inflammation cannot be attributed to the KKS or plasmatic coagulation cascade activation.

Another pathway, which is triggered by FXII, is the complement system ${ }^{15}$. Modulation of certain components of the complement system, such as $\mathrm{C} 3 \mathrm{a}$ or $\mathrm{C} 5 \mathrm{a}$, has been shown to be relevant in $\mathrm{EAE}^{22}$. However, C5a serum levels were not significantly different between WT and $\mathrm{F}^{-1-}$ animals (Supplementary Fig. 4h).

FXII is pivotal for DC to orchestrate T-cell differentiation. FXII can directly act on cells by binding to domain 2 of the glycoprotein CD87 (refs 16,18). Hence, we evaluated Cd87 expression in different immune cell subtypes isolated from the LN or spleen of naive WT mice by rRT-PCR (Fig. 3a). Interestingly, $C d 87$ expression was prominent in $\mathrm{CD}_{11 \mathrm{c}^{+}} \mathrm{DC}$, identifying those cells as a potential target of FXII. Naive $\mathrm{CD}^{+}$T-cell activation under $\mathrm{T}_{\mathrm{H}} 1-, \mathrm{T}_{\mathrm{H}} 17-$ and inducible $\mathrm{T}_{\text {reg }}$ ( $\mathrm{iT}_{\text {reg }}$ )-favouring conditions did not lead to substantial CD87 upregulation (Fig. 3b). To search for $\mathrm{CD}^{+} 7^{+}$DC subsets, we purified conventional DCs (cDCs) and plasmacytoid DCs (pDCs) from WT mouse spleens. Both cell types expressed high levels of CD87 at both the messenger RNA and protein levels (Fig. 3b,c). Further protease-activated receptors (PAR), such as PAR1-4, are also able to interact with coagulation factors ${ }^{23}$. However, in contrast to CD87, cDC and pDC expressed only low numbers of Par1-4 messenger RNA transcripts (Fig. 3d).

We examined potential immunoregulatory functions of FXII pertinent to the interaction between $\mathrm{CD} 4{ }^{+} \mathrm{T}$ cells and DC using different co-culture approaches. No significant differences in T-cell proliferation and cytokine production of IFN- $\gamma$ and IL-17A were observed when incubating $\mathrm{CD}^{+}{ }^{+} \mathrm{T}$ cells with FXII or vehicle (Supplementary Fig. 5a). In addition, $\mathrm{T}_{\mathrm{H}} 1, \mathrm{~T}_{\mathrm{H}} 17$ or Foxp3 induction in $\mathrm{CD}^{+} \mathrm{T}$ cells cultivated under $\mathrm{T}_{\mathrm{H}} 1-, \mathrm{T}_{\mathrm{H}} 17$ - and $\mathrm{iT}_{\text {reg-inducing conditions, respectively, was not significantly }}$ affected by the presence of FXII (Supplementary Fig. 5b). In contrast, FXII-treated cDCs produced higher amounts of IL-6 in response to lipopolysaccharide (LPS), as compared with control conditions, while the levels of IL-10 and IL-12 were significantly reduced (Fig. 3e). In line with the finding for IL-6, the amount of
IL-23 was also significantly higher, whereas the levels of TGF- $\beta$ and IL-27 were reduced in the presence of FXII compared with controls (Fig. 3e). However, treatment of pDCs with FXII alone or together with $\mathrm{CpG}$ oligodeoxynucleotide $1,826(\mathrm{CpG})$ did not lead to a significant shift in IL-6, IL-10, IL-23 or TGF- $\beta$ production (Fig. 3e). For cDCs, similar results were obtained using FXIIa, the active form of FXII (Fig. 4a) and a non-cleavable FXII (Fig. 4b), indicating that both the active and inactive forms of FXII can modulate cDC function. Notably, immature and mature DCs did not differ significantly in terms of expression of the different surface markers in $F 12^{-I-}$ mice compared with WT controls or after exposure to FXII (Supplementary Figs 6 and 7).

To address the hypothesis that FXII modulates $\mathrm{CDC}$ function via CD87, cDCs of CD87-deficient $\left(C d 87^{-1-}\right)$ mice were treated with FXII or vehicle in the presence of LPS. In this scenario, CDC cytokine levels of IL-6, IL-12, TGF- $\beta$ and IL-27 were not affected by FXII, indicating that CD87 on DCs is the main receptor mediating the effects of FXII (Fig. 4c). However, as CD87 is a glycoprotein without an intracellular domain and cannot induce intracellular signalling by itself, we sought to determine whether further transmembrane receptors are necessary to initiate intracellular signalling. Previous evidence has suggested that CD87 may form lateral complexes with $\beta_{2}$-integrins, such as Mac-1 integrin (also designated $\mathrm{CD} 1 \mathrm{lb} / \mathrm{CD} 18$ ), which could thereby serve as mediators of CD87-triggered signalling events $^{24,25}$. Thus, we engaged CD11b-deficient Itgam $^{-1-}$ ) cDCs, which we treated with FXII or vehicle in the presence of LPS. FXII failed to induce changes in the production of cytokines in CD11b-deficient CDCs, indicating that the ligation of CD87 by FXII induces intracellular signalling in a CD11b-dependent manner (Fig. 4d).

Pathways inducing enhanced cyclic AMP (cAMP) formation in DCs are triggered by LPS and enhance cytokines associated with $\mathrm{T}_{\mathrm{H}} 17$ responses, such as IL-6 and IL-23, while decreasing $\mathrm{T}_{\mathrm{H}} 1$-associated cytokines, such as IL-12 and IL-27 (refs 26,27). We therefore challenged WT cDCs with LPS in the presence and absence of FXII. Although FXII had only a slight effect on basal cAMP levels, it further increased the intracellular cAMP induced in cDCs by LPS (Fig. 4e). This effect was again CD87 dependent, as FXII failed to alter intracellular cAMP levels in Cd87-deficient DCs (Fig. 4e). Furthermore, production of $\mathrm{T}_{\mathrm{H}} 17$-associated cytokines was also reduced by treating WT cDCs with FXII in combination with different protein kinase A signalling inhibitors (Fig. 4f), indicating no significant role of protein kinase A-independent pathways of cAMP.

We obtained consistent results using $\mathrm{DC}^{-\mathrm{CD}} 4^{+} \mathrm{T}$-cell co-cultures. Under unskewed co-culture conditions (WT or Cd87 $7^{-1-} \mathrm{CD} 4^{+}$T cells and WT DCs), FXII reduced IFN- $\gamma$ and increased IL-17A, IL-6 and IL-23 (Fig. 4g). In contrast, cytokine levels of $C d 87^{-1}$ DCs co-cultured with WT or $C d 87^{-1-}$ $\mathrm{CD} 4{ }^{+} \mathrm{T}$ cells were not significantly different from controls (Fig. 4g). To prove that CD87 is also relevant in vivo, an AT model was created using $\mathrm{CD} 4^{+} \mathrm{T}$ cells and $\mathrm{DCs}$ isolated from WT and $C d 87^{-1-}$ mice restimulated in the presence or absence of FXII (Fig. 5a). Interestingly, WT mice treated with FXIIrestimulated WT CD4 ${ }^{+}$T cells and DCs displayed an aggravated disease course, while FXII had no additional effect on CD87deficient $\mathrm{CD} 4{ }^{+} \mathrm{T}$ cells and DCs. Of note, transfer of $\mathrm{Cd} 87^{-1-}$ $\mathrm{CD} 4^{+} \mathrm{T}$ cells and DCs led to an attenuated disease course, as compared with control conditions (Fig. 5a).

To address a relevant role of CD87 also on resident cells, bone marrow (BM) chimeras were created by transferring WT or $C d 87^{-1-}$ BM into WT and $C d 87^{-1-}$ hosts after irradiation. $C d 87^{-1-}$ or WT mice reconstituted with $C d 87^{-1-}$ BM were less susceptible to the development of EAE compared with WT 
a

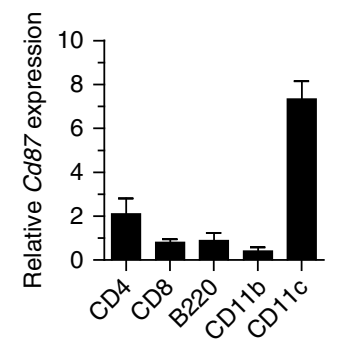

b

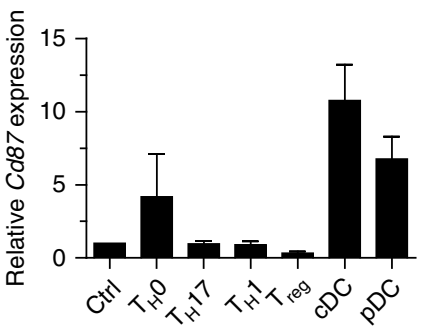

C
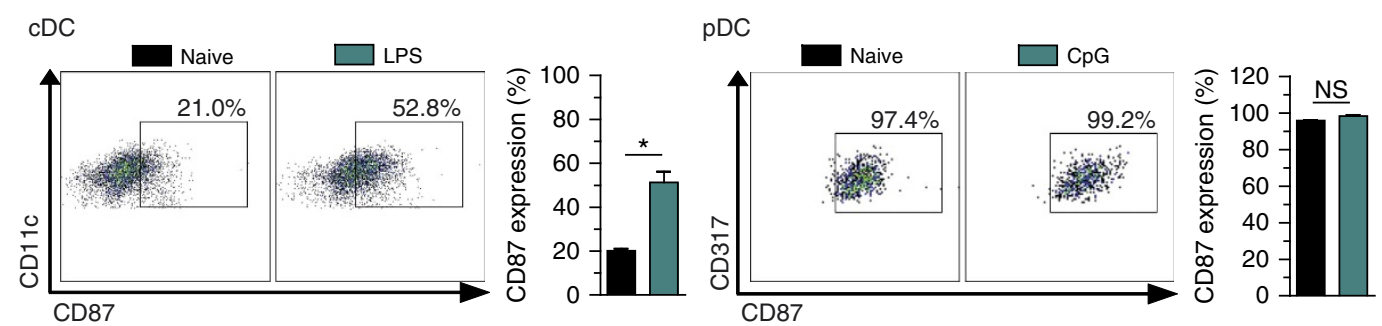

d

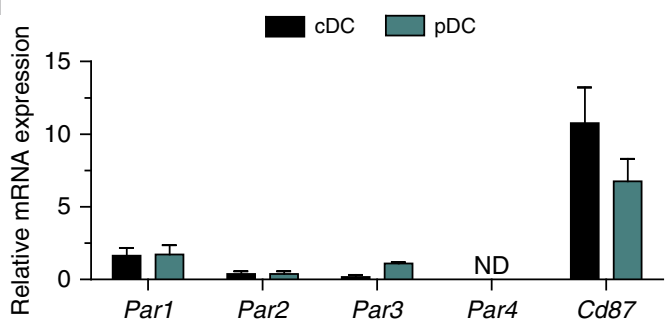

e $\quad \mathrm{DDC}$

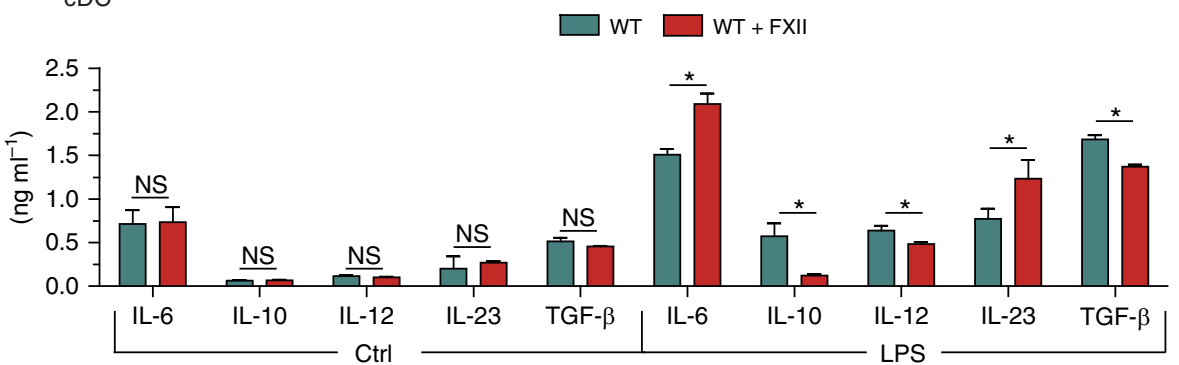

$\mathrm{CDC}$
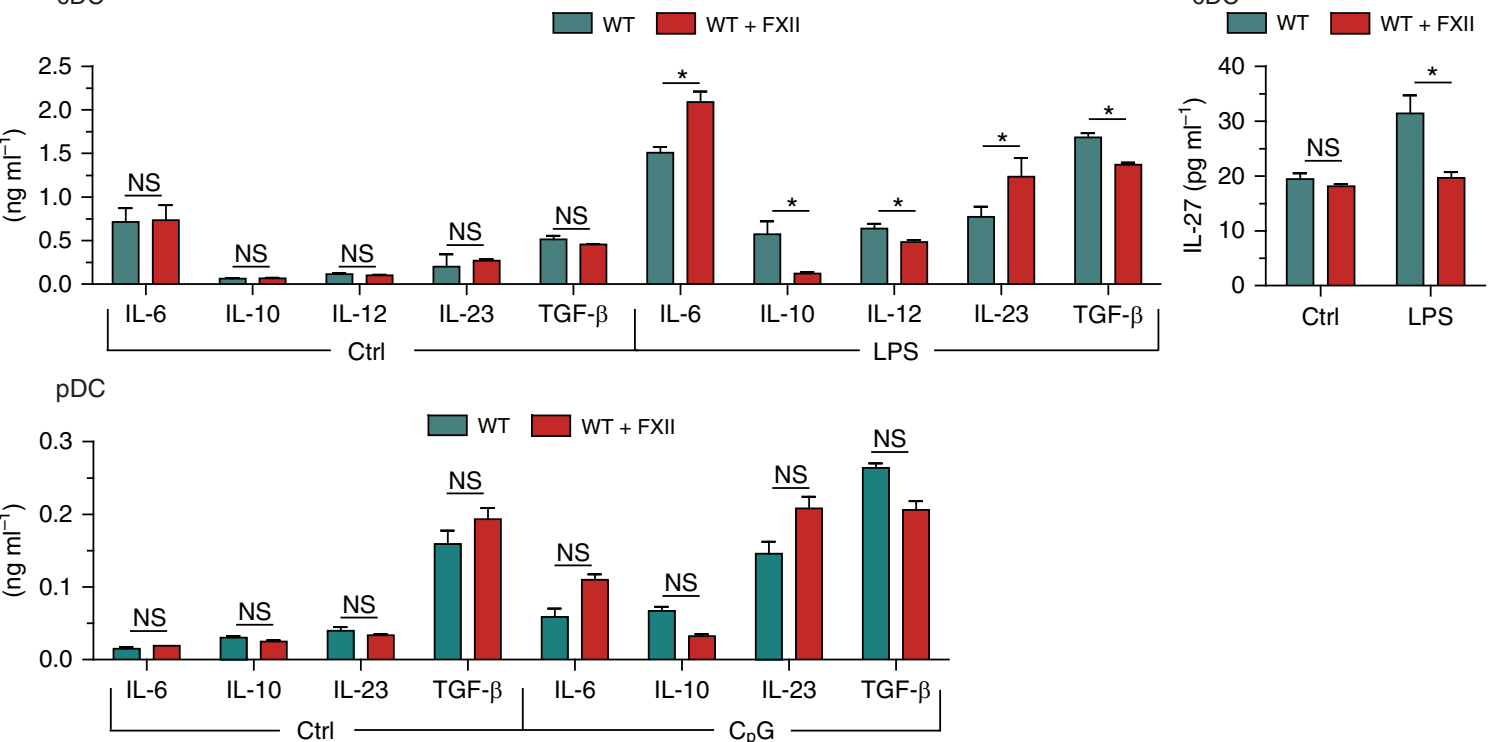

Figure 3 | FXII favours the emergence of $\mathbf{T}_{\mathbf{H}} 17$ cells via DC. (a) Real-time reverse transcription-PCR (rRT-PCR) analyses for Cd87 gene expression in $\mathrm{CD}^{+}, \mathrm{CD}^{+}$and $\mathrm{B220}{ }^{+}$cells isolated from lymphocytes as well as in $\mathrm{CD}_{11 b^{+}}$and $\mathrm{CD} 11 \mathrm{c}^{+}$cells isolated from spleens of naive WT mice. (b) rRT-PCR analyses for $\mathrm{Cd} 87$ gene expression in $\mathrm{CD} 4{ }^{+} \mathrm{CD}_{25}{ }^{-}$(Crtl) and $\mathrm{CD} 4{ }^{+} \mathrm{CD}_{25}{ }^{+}\left(\mathrm{T}_{\text {reg }}\right)$ cells isolated from lymph nodes under basal conditions or after a $48-\mathrm{h}$ incubation with antibodies against $C D 3$ and $C D 28$ under neutral conditions $\left(T_{H} O\right)$ or in the presence of the appropriate cytokine and neutralizing antibody mixtures for differentiation into $T_{H} 1$ or $T_{H} 17$ cells as well as in splenic $C D C s$ or pDCs. (c) Flow cytometry analysis for CD87 expression in cDCs (stained with CD11c, left panel) and pDCs (stained with CD317, right panel) isolated from the spleen under basal conditions or after a 24-h stimulation with $1 \mu \mathrm{gl}^{-1} \mathrm{LPS}$ or $10 \mu \mathrm{g} \mathrm{ml}^{-1} \mathrm{CpG}$ oligodeoxynucleotide 1,826, respectively. For CDCs and $\mathrm{pDCs}$, representative dot plots for CD87 expression are shown. (d) rRT-PCR analyses for Par1, Par2, Par3, Par4 and Cd87 expression in cDCs and pDCs isolated from the spleen. (e) Splenic cDCs and pDCs from WT animals were incubated with medium only (Ctrl) or stimulated with $1 \mu \mathrm{g} \mathrm{ml} \mathrm{I}^{-1} \mathrm{LPS}$ (for cDCs) or with $10 \mu \mathrm{g} \mathrm{ml}{ }^{-1} \mathrm{CpG}$ oligodeoxynucleotide 1,826 (for pDCs) in the absence or presence of $60 \mathrm{nM} \mathrm{FXII,} \mathrm{respectively.} \mathrm{After} 48 \mathrm{~h}$, cytokine concentrations were measured in culture supernatants. In $\mathbf{a}, \mathbf{b}$ and $\mathbf{d}$, data are given as mean \pm s.e.m. of three independent experiments and presented as fold change in transcript expression relative to $18 S$ rRNA. In $\mathbf{c}$ and $\mathbf{e}$, data are given as mean \pm s.e.m. of three independent experiments, each performed in triplicate (non-parametric Mann-Whitney U-test). ${ }^{\star} P<0.05 ; \mathrm{ND}$, not detected; NS, not significant. 
a

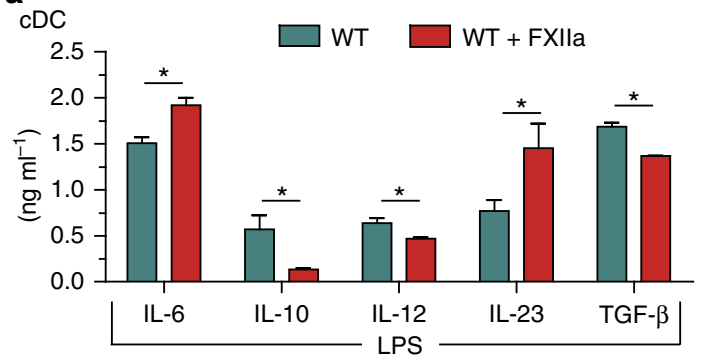

c

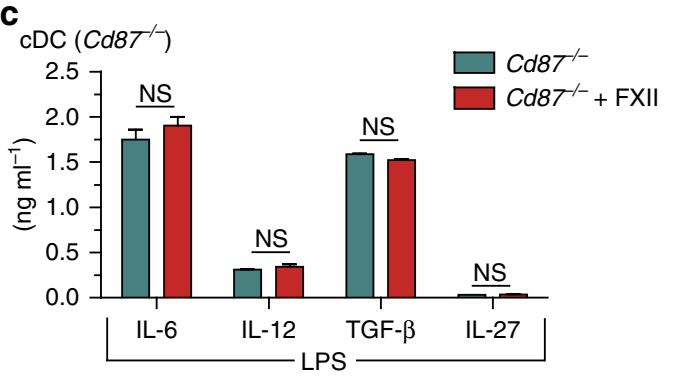

b

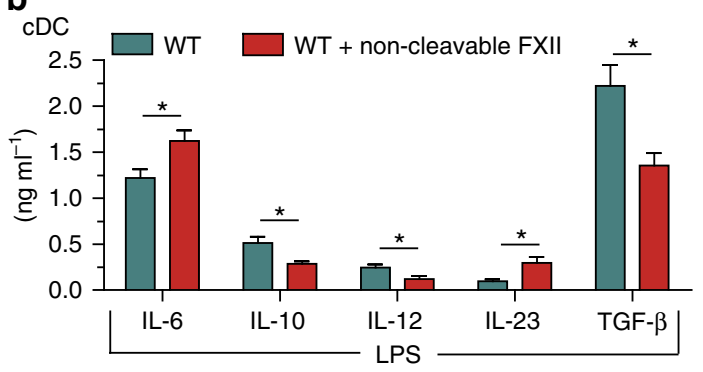

d
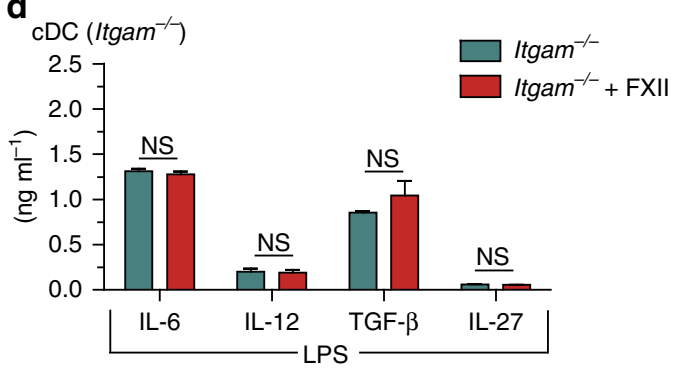
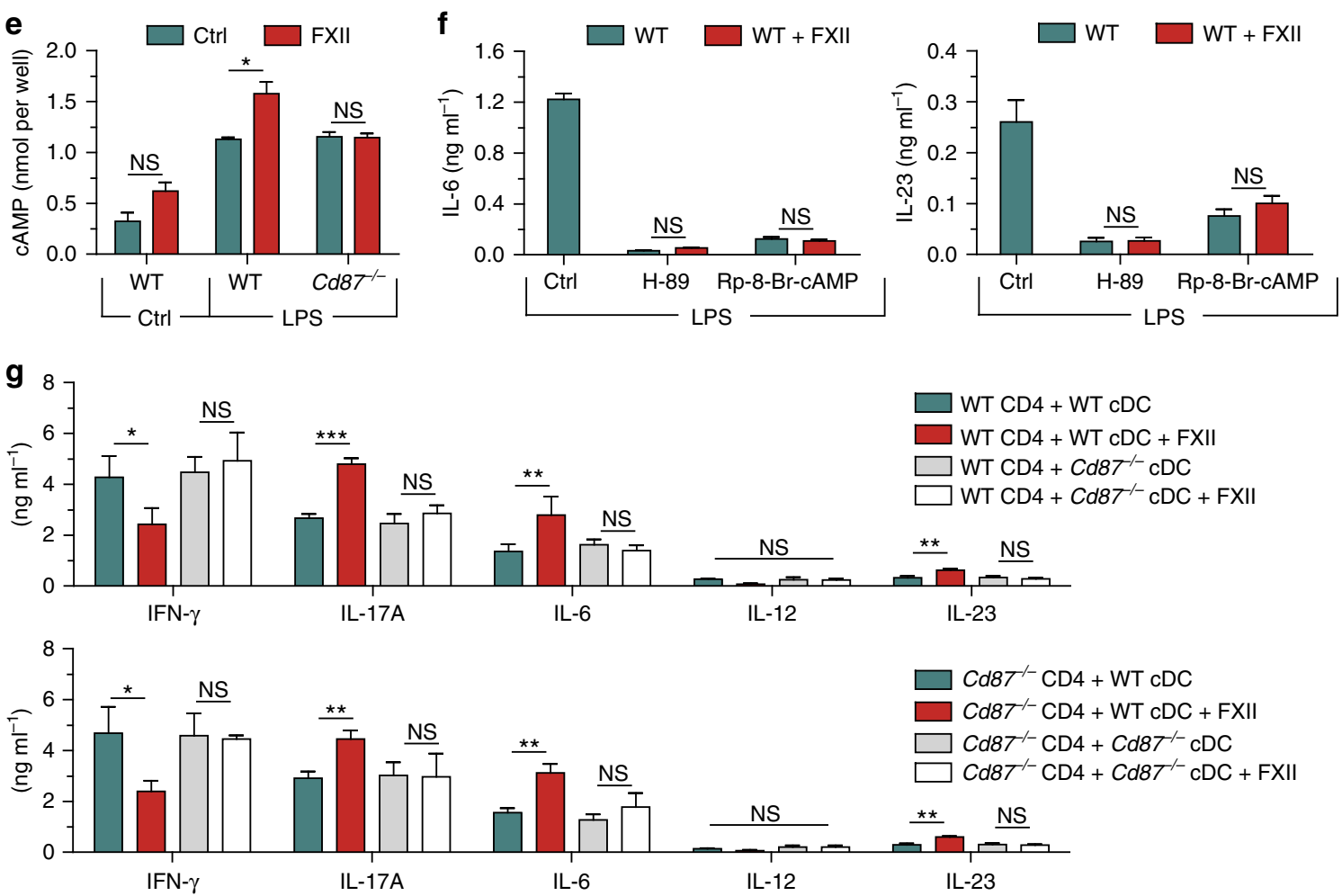

Figure 4 | FXII controls cytokine production via CD87. (a) Splenic cDCs from naive WT animals were stimulated with $1 \mu \mathrm{g} \mathrm{ml} \mathrm{I}^{-1}$ LPS in the absence and presence of $60 \mathrm{nM}$ activated FXII (FXIla). After $48 \mathrm{~h}$, cytokine concentrations were measured in culture supernatants by ELISA. (b) Cytokine production of splenic cDCs from WT animals stimulated with $1 \mu \mathrm{g} \mathrm{ml} \mathrm{m}^{-1} \mathrm{LPS}$ in the absence and presence of $60 \mathrm{nM}$ non-cleavable FXII. After $48 \mathrm{~h}$, cytokine concentrations were determined in culture supernatants by ELISA. (c) Cytokine production of splenic cDCs from CD87-deficient (Cd87-/-) mice stimulated with $1 \mu \mathrm{g} \mathrm{ml}^{-1}$ LPS alone or in the absence and presence of $60 \mathrm{nM} \mathrm{FXII} \mathrm{for} 48 \mathrm{~h}$. (d) Cytokine production of splenic cDCs from CD11b-deficient (Itgam ${ }^{-/-}$) animals stimulated with $1 \mu \mathrm{g} \mathrm{ml}^{-1}$ LPS in the absence and presence of $60 \mathrm{nM} \mathrm{FXII} \mathrm{for} 48 \mathrm{~h}$. (e) Cytosolic cAMP formation measured in cDCs from WT or $\mathrm{Cd}_{87^{-} /-}$mice that were incubated with medium only (Ctrl) or stimulated with $1 \mu \mathrm{g} \mathrm{ml} \mathrm{I}^{-1}$ LPS for 10 min in the absence (Ctrl) or presence of $60 \mathrm{nM}$ FXII. (f) Cytokine concentrations of IL-6 (left panel) and IL-23 (right panel) in the supernatants of WT cDCs stimulated with $1 \mu \mathrm{g}$ ml ${ }^{-1}$ LPS or $60 \mathrm{nM}$ FXII for $48 \mathrm{~h}$ in the presence of protein kinase A inhibitors ( $3 \mu \mathrm{M} \mathrm{H}-89$ and $100 \mu \mathrm{M} \mathrm{Rp-8-Br-cAMP).} \mathrm{(g)} \mathrm{Cytokine} \mathrm{concentrations} \mathrm{of} \mathrm{IFN-} \gamma$, IL-17A, IL-6, IL-12 and IL-23 were measured in the supernatants from co-cultures of CD4 ${ }^{+} \mathrm{T}$ lymphocytes from WT (upper panel) or $\mathrm{Cd} 87^{-/-}$(lower panel) that were polyclonal activated together with cDCs from WT and $\mathrm{Cd}_{8} 87^{-/-}$in the absence or presence of $60 \mathrm{nM} \mathrm{FXII.} \mathrm{In} \mathrm{a-g,} \mathrm{data} \mathrm{are} \mathrm{given} \mathrm{as} \mathrm{means} \pm$ s.e.m. of three independent experiments, each performed in duplicate (non-parametric Mann-Whitney $U$-test). ${ }^{\star} P<0.05,{ }^{\star \star} P<0.01,{ }^{\star \star \star} P<0.001$;

NS, not significant. 
a

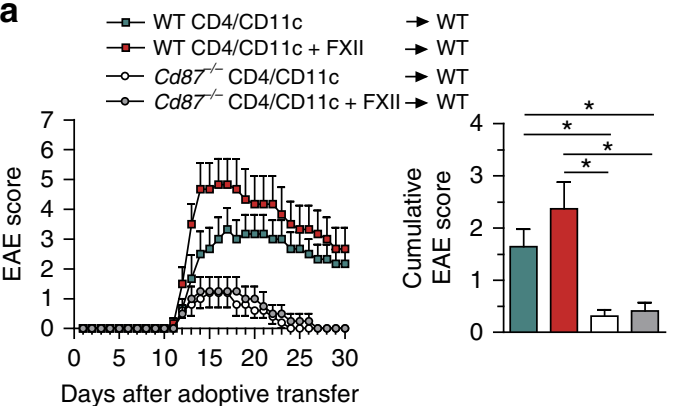

b
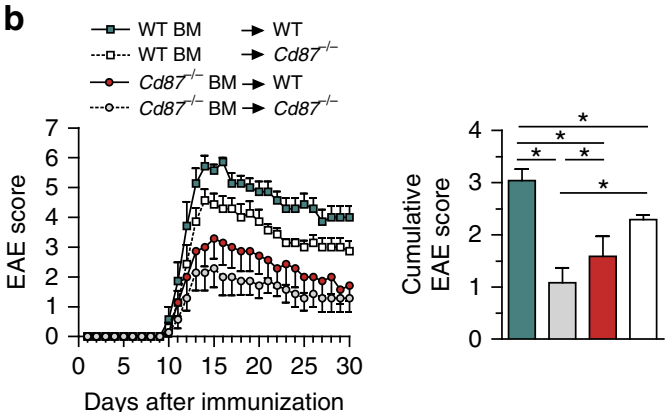

C
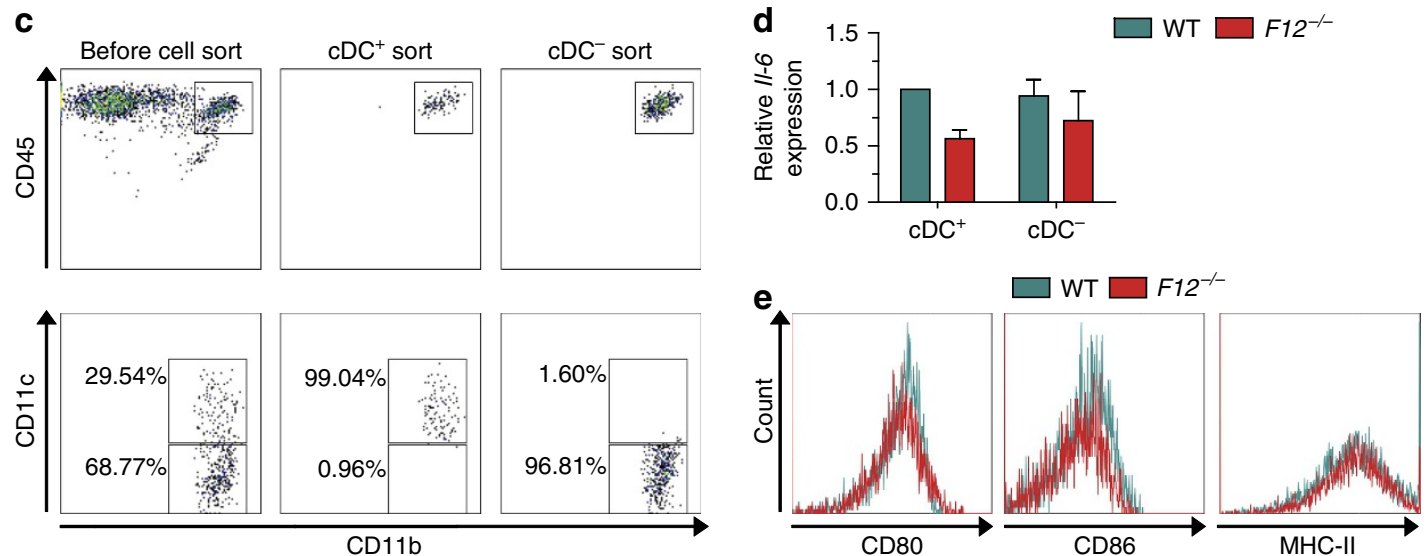

MHC-II
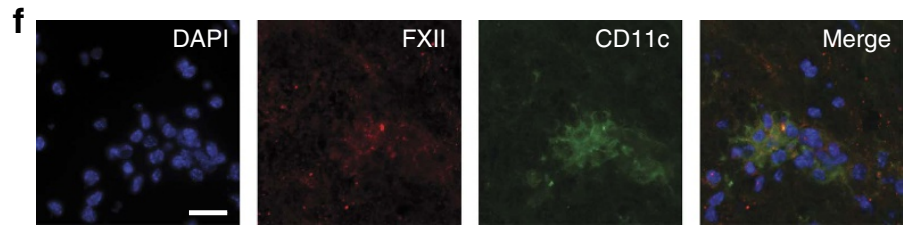

Figure 5 | FXII influences DCs in the CNS. (a) EAE development is shown in WT mice after adoptive transfer of CD4 ${ }^{+}$lymphocytes and CD11c ${ }^{+}$cells isolated from WT or $\mathrm{Cd}_{87^{-/}}$- mice on day 12 post immunization and restimulated with $10 \mu \mathrm{g} \mathrm{ml}^{-1} \mathrm{MOG}_{35-55}$ and $0.5 \mathrm{ng} \mathrm{ml}{ }^{-1} \mathrm{IL}-12$ with or without $60 \mathrm{nM}$ FXII for $72 \mathrm{~h}$. Mean clinical and mean cumulative scores \pm s.e.m. over time of three independent experiments are given (non-parametric

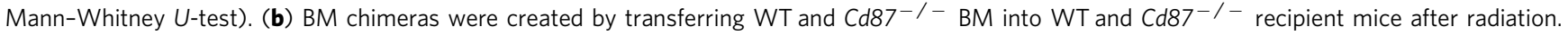
Mean clinical and mean cumulative scores \pm s.e.m. of EAE from three independent experiments are shown (non-parametric Mann-Whitney $U$-test).

$(\mathbf{c}, \mathbf{d})$ Brain-infiltrating leukocytes (BILs) were separated into $\mathrm{CDC}^{+}$and $\mathrm{CDC}^{-}$by sorting via flow cytometry based on indicated surface markers at $d_{\text {max }}$ after EAE induction. Both subsets from WT or $\mathrm{F}^{-2^{-/}}$mice were analysed for $11-6$ expression by real-time reverse transcription-PCR using $18 \mathrm{~s}$ rRNA for normalization. Data are given as mean \pm s.e.m. of two experiments, each experiment generated from pooled brain and spinal-cord-derived cells of $n=6-7$ mice per group and presented as fold change in normalized gene expression relative to WT controls. (e) Flow cytometric analysis of BILs from WT and $F 12^{-/-}$animals at $d_{\max }$ after EAE induction determined the expression of CD80, CD86 and MHC-II in CDCs that were pre-gated for CD45 high CD11b ${ }^{+}$

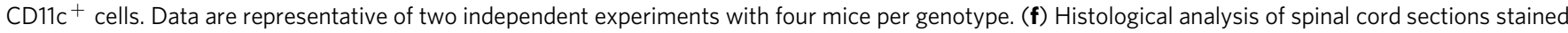
for the nucleus (4,6-diamidino-2-phenylindole (DAPI), blue), FXII (red) and CD11c (green) from the lumbar region of EAE WT animals at $d_{\text {max. }}$ Scale bar, $100 \mu \mathrm{m} .{ }^{\star} P<0.05$.

mice reconstituted with WT BM (Fig. 5b). Interestingly, transfer of WT BM into $C d 87^{-/-}$animals led to a partial protection (Fig. 5b) arguing for a role of FXII on both peripheral and resident cells.

CD87 is also expressed on endothelial, microglial and astroglial cells (Supplementary Fig. 8a). Hence, we isolated MBMECs from WT mice and treated them with FXII under naive and inflammatory conditions. While inflammation led to a significant reduction of transendothelial resistance (TER), FXII had no additional effect (Supplementary Fig. 8b). Furthermore, while MIP-1 $\beta$ production of MBMECs was increased in the presence of FXII, other chemokines were not influenced (unaltered level of CXCL1, CXCL9, CXCL10, CCL2, MIP-1 $\alpha$, RANTES, CCL11, CCL17 and CCL22; no detection of CCL20, CXCL5 and CXCL13; Supplementary Fig. 8c). To exclude a direct effect of FXII on transmigration, we analysed the impact of FXII on the migratory capacity of immune cells in an in vitro transmigration assay. The number of immune cells crossing the MBMEC barrier did not change in the absence or presence of FXII (Supplementary Fig. 8d). To analyse the potential effect of FXII on microglia and astrocytes, primary cultures were prepared. However, FXII did not affect major histocompatibility complex (MHC)-I or -II, or production of IL-6, IL-10 and tumour necrosis factor $\alpha$ (TNF- $\alpha$ ) cytokines in both microglia (Supplementary Fig. 8e,g) and astrocytes (Supplementary Fig. 8f,h). Of note, the number of activated microglia and astrocytes was unchanged in FXII-deficient animals compared with WT controls on $d_{\max }$ of EAE (Supplementary Fig. 8i,j).

As extensive FXII depositions were found in the CNS of immunized mice (Fig. 1a,b), we analysed the possible effect of FXII on cDCs present in the CNS on $d_{\max }$ of EAE mice. Therefore, we separated cDCs from the CNS on $d_{\max }$ (Fig. $5 \mathrm{c}$ ). 
Interestingly, cDCs isolated from $F 12^{-/-}$mice showed again a reduction in IL-6 levels (Fig. 5d), while the surface markers CD80, CD86 and MHC-II were unchanged (Fig. 5e). Furthermore, FXII depositions were localized in the close proximity of DCs in the inflamed spinal cord (Fig. 5f).

Pharmacologic inhibition of FXII protects from EAE. Since FXII deficiency prevented EAE, we investigated whether the effect of FXII deficiency could be mimicked using the highly specific FXII inhibitor, recombinant human albumin (rHA)-Infestin-4 (ref. 28). Indeed, rHA-Infestin-4, starting 1 day after $\mathrm{MOG}_{35-55}$ immunization, significantly attenuated the signs of EAE in WT mice (Fig. 6a; Supplementary Table 3) and was able to ameliorate cellular inflammation and demyelination (Fig. 6b,c). Again, the protective effect of rHA-Infestin- 4 in WT mice was associated with a reduced $\mathrm{T}_{\mathrm{H}} 17$ immune response (Fig. 6d). In contrast, rHA-Infestin-4 could no longer alter the EAE disease course when applied after neurologic symptom onset (Fig. 6e). Interestingly, rHA-Infestin-4 could not be found in the CNS of EAE mice, indicating no significant entrance of the substance through the BBB into the CNS (Supplementary Fig. 9). These findings point again to both a predominant role of FXII in DC-mediated EAE disease priming and influence on resident APCs.

To further demonstrate that FXII inhibition represents a promising new approach to combat MS, we challenged SJL/JRj mice in a relapsing-remitting-EAE (RR-EAE) model ${ }^{29}$. FXII inhibition significantly reduced the number and severity of relapses, even when rHA-Infestin-4 was injected in a delayed setting, that is, not until the first clinical attack (Fig. 6f; Supplementary Table 4). Furthermore, the inhibition of FXII was challenged in a spontaneous model of EAE that has been used in our group before ${ }^{30}$. For this purpose, double transgenic Devic mice were generated by crossbreeding transgenic mice carrying either a $\mathrm{MOG}_{35-55}$-specific T-cell receptor (TCR) or

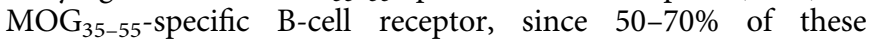
mice spontaneously develop EAE-like symptoms without the administration of any substances used for immunization ${ }^{31}$. Littermates were treated daily with rHA-Infestin- $4\left(200 \mathrm{mg} \mathrm{kg}^{-1}\right.$ body weight) or vehicle for 20 consecutive days, starting at postnatal day 20. Devic mice treated with rHA-Infestin-4 displayed attenuated clinical symptoms (Fig. 6g,h), sustained motor coordination, as revealed by rotarod analysis (Fig. 6i), and a limited number of CNS-infiltrating CD ${ }^{+} \mathrm{T}$ cells (Fig. 6j).

To further analyse the functional relevance of FXII in adaptive immunity, we introduced a skin contact hypersensitivity model in which $\mathrm{T}_{\mathrm{H}} 17$ cells are critically involved in disease pathogenesis. In this model, mice are immunized by painting dinitrofluorobenzene on the shaved abdomen on day 0 and undergo antigen rechallenge on day 5 by painting the same antigen on the ear. Ear thickness and the underlying immune responses are assessed 1 day later. $F 12^{-I-}$ mice developed less inflammation in the challenged ear and less IL-17A production from $\mathrm{T}$ cells, while proliferation and IFN- $\gamma$ production were unchanged (Fig. 6k), suggesting that FXII deficiency can inhibit $\mathrm{T}_{\mathrm{H}} 17$ cell development, not only under neuroinflammatory conditions but also in other immune disorders.

FXII is upregulated in MS patients. To assess the involvement of FXII in humans, we analysed the plasma from individuals with different forms of MS (clinically isolated syndrome, relapsingremitting MS, primary progressive MS and secondary progressive MS, Supplementary Table 5). FXII plasma level was significantly increased in patients with relapsing-remitting MS and secondary progressive MS compared with healthy donors (HDs; Fig. 7a). Interestingly, enhanced FXII amount was observed during the course of a relapse (Fig. 7b). Moreover, FXII levels tended to correlate with disease activity, as higher levels were associated with a shorter relapse-free period, independent of immunomodulatory therapy (Fig. 7c). In addition to these peripheral alterations, extensive FXII depositions could be found in the CNS of individuals with MS, but not in HDs (Fig. 7d). These depositions were in close contact with DCs, indicating that these cells may be the potential targets of FXII in the CNS of MS patients as well (Fig. 7e). As mouse data suggest an immunomodulatory function of FXII on DCs, also in the periphery, we examined the influence of FXII on these cells in humans (Fig. 7f). Interestingly, in contrast to the mouse data, FXII led to an extensive upregulation of the co-stimulatory molecules CD80 and CD86 in human DCs (Fig. 7g,h), while CD40 and MHC-II expression was unaltered (Fig. 7i,j). Furthermore, CD87, the proposed binding partner of FXII, was significantly increased in human DCs on FXII treatment (Fig. 7k). Together, these data suggest that FXII also significantly enhanced the amount of IL-6 and IL-23 (Fig. 7l), indicating a significant immunomodulatory role of FXII, not only in mice but also in humans.

\section{Discussion}

Immune inflammation triggered by pathogenic and/or autoreactive $T_{H}$ cells underlies various immune diseases $3,32,33$. To our knowledge, our work represents major novel insights into the role of a plasmatic coagulation cascade member as a critical trigger of autoimmune inflammation. Genetic deficiency or pharmacologic blockade of FXII significantly protected from EAE in different clinically relevant settings. Mechanistically, FXII stimulates DC-mediated $\mathrm{T}_{\mathrm{H}} 17$-cell generation in a CD87-dependent manner. Importantly, FXII deficiency also ameliorated skin allergy, thereby underpinning the pathophysiologic importance of this coagulation factor in adaptive immunity, and thus as a potential therapeutic target in autoimmunity.

The traditional view of plasmatic coagulation cascade is linked to thrombotic diseases ${ }^{19}$. However, there is increasing evidence that some coagulation factors may also be involved in autoimmune disorders, such as in MS, inflammatory bowel disease or dermatitis ${ }^{34-36}$. Depositions of fibrinogen and the degradation products thereof were found in the CNS and skin of patients with MS or dermatitis ${ }^{34-36}$. In the brain, those depositions fostered microglia activation and subsequent plaque formation $^{12,36}$. Moreover, a close correlation between the cerebral or spinal fibrin load and the number of relapses was reported in EAE mice, and anticoagulant administration or fibrinogen depletion reversed the pathology ${ }^{14,37}$. Apart from triggering thrombus formation via the intrinsic pathway of blood coagulation, FXII is also central to the triggering of the proinflammatory KKS, leading to the formation of $\mathrm{BK}$. The physiologic and pathophysiologic effects of BK are mediated by two distinct $\mathrm{BK}$ receptors ${ }^{38}$. Human studies revealed that $\mathrm{B} 1 \mathrm{R}$ is expressed on circulating lymphocytes and infiltrating $\mathrm{T}$ cells during active episodes of MS. Moreover, B1R can be found on endothelial cells within MS plaques ${ }^{39-41}$. In the EAE model, contradictory reports exist with regard to the relevance of $\mathrm{B} 1 \mathrm{R}$ and $\mathrm{B} 2 \mathrm{R}^{21,42}$

While the immune system of FXII-deficient mice was dominated by a protective response with a reduction in $\mathrm{T}_{\mathrm{H}} 17$ cells, we found that, for this shift, neither the coagulation system nor the KKS was required. This unexpected observation led us to hypothesize that FXII might affect the immune system via CD87 (ref. 18).

CD87 is a glycoprotein tethered to the cell membrane with a glycosylphosphatidylinositol anchor. CD87 was originally identified as a binding site for urokinase on the surface of different cells, 
but can also be activated by FXII ${ }^{18}$. Indeed, cDCs and pDCs isolated from the periphery constitutively expressed CD87, as did activated CD4 ${ }^{+}$T cells. Most notably, FXII tipped the balance of $\mathrm{T}$-cell differentiation towards a $\mathrm{T}_{\mathrm{H}} 17$ phenotype, which is increasingly being recognized as a key player in MS pathophysiology 8,43 . This effect of FXII critically depended on the presence of CD87 in cDCs. Moreover, since CD87 lacks an intracellular domain, we identified the CD11b integrin, which was previously shown to interact with CD87 on the membrane ${ }^{24,25}$, as the adapter-mediating intracellular signalling and cytokine upregulation triggered by FXII.

Our data suggest that FXII acts on peripheral DCs, thereby shaping T-cell differentiation and adaptive immunity. FXII was also found in the CNS during neuroinflammation, indicating a a

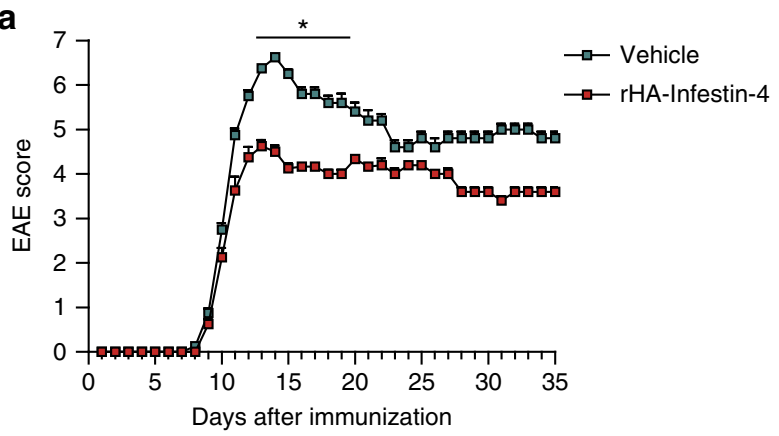

b

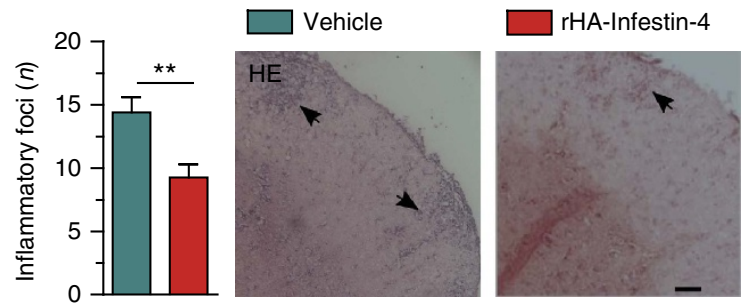

c

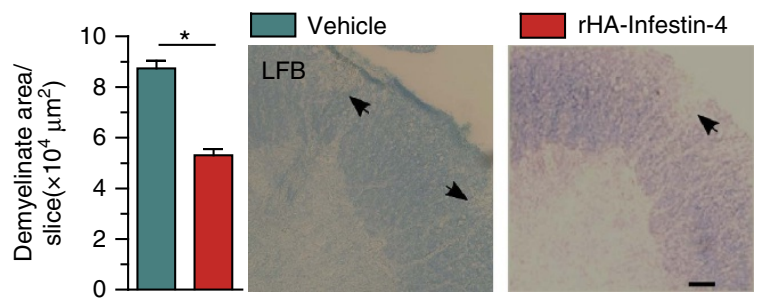

d

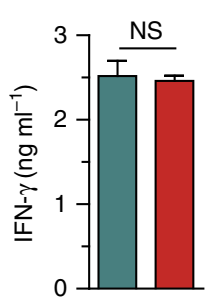

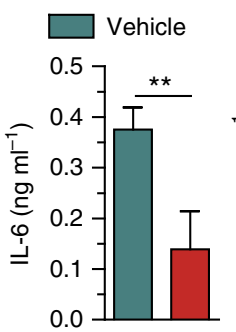
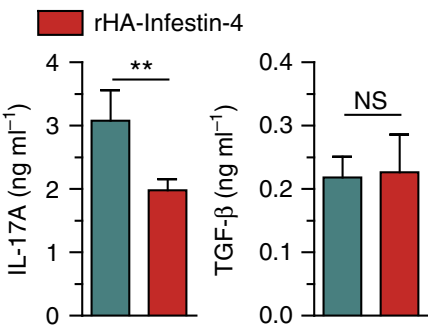
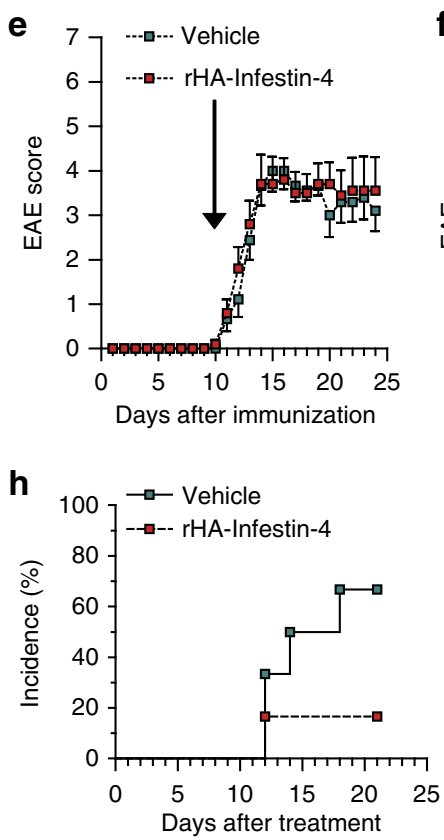

k

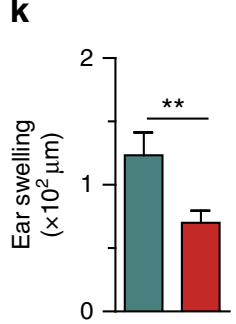

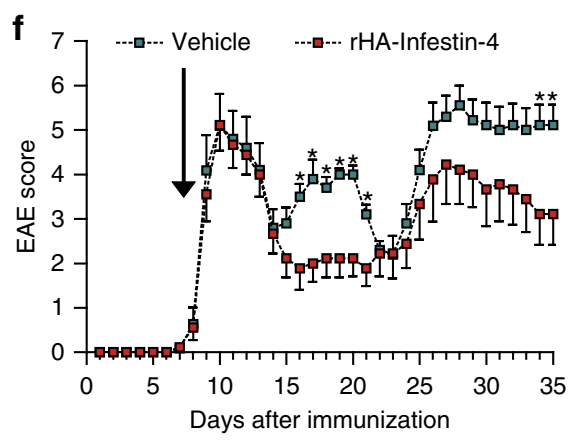
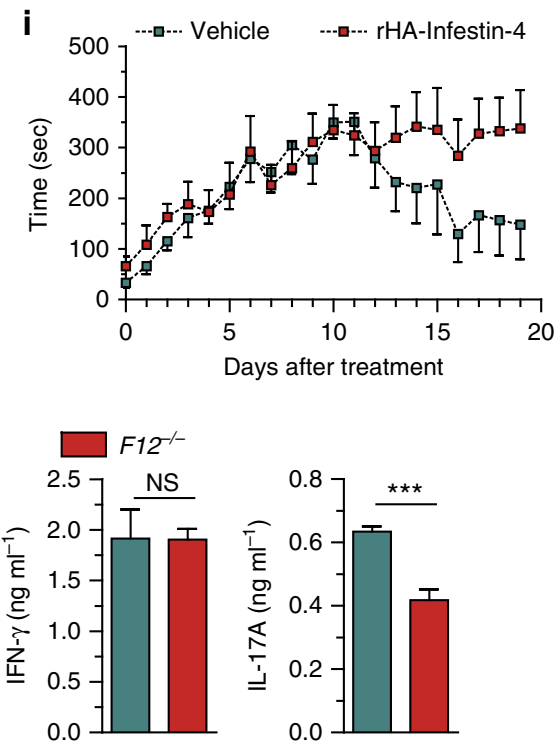

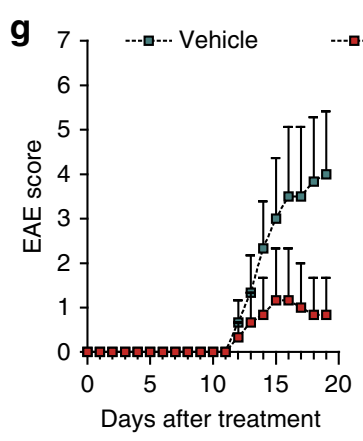

-.-. rHA-Infestin-4
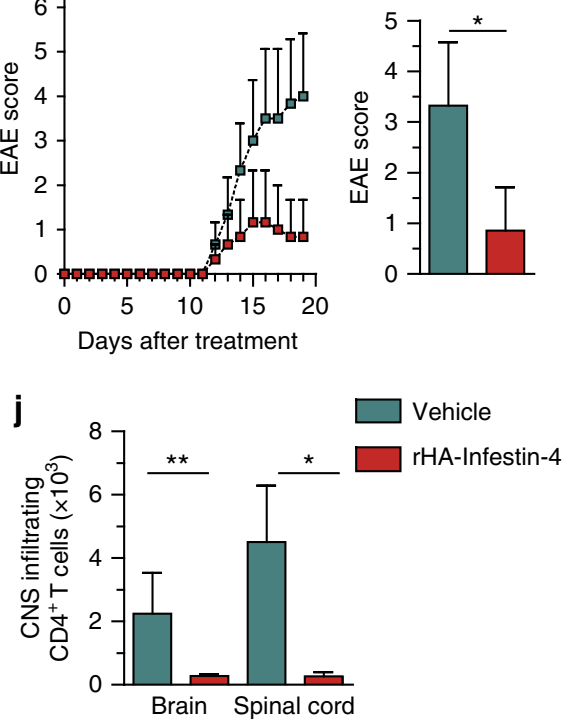
significant local role. Resident cells such as microglia, astrocytes and endothelial cells are known to express CD87. However, none of these cells could be identified as a relevant target of FXII in our model. Nevertheless, FXII was able to induce a cytokine shift in DCs localized in the CNS during neuroinflammation. DCs can regulate $\mathrm{T}$-cell function and are capable of integrating a myriad of incoming immune signals to govern downstream circuits ${ }^{4,45}$. We here provide evidence that CD87 activation through FXII impacts the cytokine responses to inflammatory signals and yields a typical $\mathrm{T}_{\mathrm{H}} 17$ cytokine network by boosting IL-6 production under neuroinflammatory conditions.

From a translational perspective, FXII blockade in WT mice with the highly specific FXII inhibitor rHA-Infestin-4 had a beneficial effect on disease severity and progression in different EAE models. Since rHA-Infestin-4 has anticoagulant properties and potentially interferes with hemostasis, there might be a considerable risk of inducing bleeding complications when using this compound. However, previous experimental stroke and thrombosis studies revealed that neither $F 12^{-I}-$ nor WT mice treated with rHA-infestin-4 developed a bleeding phenotype ${ }^{19,28}$. This is in line with the notion that FXII is dispensable for hemostasis, but only contributes to thrombosis ${ }^{16}$. The fact that FXII inactivation does not affect hemostasis makes FXII inhibition a safe pharmacologic approach, at least in rodents ${ }^{46}$. Whether this also applies to humans, and particularly in the course of autoimmune CNS inflammation, needs to be elucidated. Notably, we never observed any major haemorrhages in the organs of $F 12^{-/}$mice subjected to EAE (not shown).

Overall, our study identifies FXII as a key regulator of adaptive immune responses during neuroinflammation. Targeted inhibition of FXII might become a promising approach to redress immune balance in MS. Further studies in relevant preclinical disease models are warranted.

\section{Methods}

Mice. C57BL/6N mice, which served as controls (WT), and SJL/JRj mice were purchased from Charles River Laboratories (Sulzfeld, Germany). FXII-deficient $\left(F 12^{-l-}\right)^{19}$, factor XI-deficient $\left(F 11^{-l-}\right)^{19}$, B1R-deficient $\left(B 1 r^{-l-}\right)^{21}$ and B2R-deficient $\left(B 2 r^{-1-}\right)$ mice $^{21}$ were a gift from C. Kleinschnitz (Department of Neurology, University Hospital Würzburg, Würzburg, Germany). CD11b-deficient $\left(\text { Itgam }{ }^{-1-}\right)^{47}$ mice and CD87-deficient $\left(C d 87^{-I-}\right)^{48}$ animals were obtained from T. Chavakis (Department of Clinical Pathobiochemistry and Institute for Clinical Chemistry and Laboratory Medicine, University Clinic Carl Gustav Carus, Technische Universität of Dresden, Dresden, Germany) and C. Ruppert (Department of Internal Medicine, Universities of Giessen \& Marburg Lung Center (UGMLC)/Member of the German Center for Lung Research (DZL), Justus-Liebig University, Giessen, Germany), respectively. Transgenic $2 \mathrm{D} 2\left(T C R^{\mathrm{MOG}}\right)$ and $\mathrm{Th}\left(\mathrm{IgH} \mathrm{MOG}^{\mathrm{MOG}}\right)$ mice from the laboratory of $\mathrm{H}$. Wekerle (Department of Neuroimmunology, Max Planck Institute for Neurobiology, Martinsried, Germany) were also used ${ }^{31}$. All mice, except SJL/JRj, had a C57BL/6 background. All animal experiments were performed on adult mice at 8-10 weeks of age.
All animal protocols were approved by the local authorities, and were in accordance with the German laws and regulations for animal care.

Induction and evaluation of EAE. Active EAE was induced by immunization of 8-10-week-old female F12 ${ }^{-I-}, F 11^{-I-}$ and WT (C57BL/6N) mice with $\mathrm{MOG}_{35-55}$ peptide (Charité, Berlin, Germany) ${ }^{21}$. Briefly, animals were subcutaneously immunized with $200 \mu \mathrm{g}$ of the mouse $\mathrm{MOG}_{35-55}$ peptide emulsified in $200 \mu \mathrm{l}$ complete Freund's adjuvant (Sigma-Aldrich Chemie GmbH, Steinheim, Germany) containing $200 \mu \mathrm{g}$ Mycobacterium tuberculosis (strain H37 Ra; Becton, Dickinson and Company (BD), Sparks, MD, USA). Pertussis toxin (PTx; $400 \mathrm{ng}$ in $200 \mu \mathrm{l}$ PBS; Enzo Life Sciences, Farmingdale, NY, USA) was injected intraperitoneally (i.p.) on the day of immunization (day 0) and 2 days later. Some mice were treated daily with intravenous (i.v.) injections of FXII $\left(200 \mathrm{mg} \mathrm{kg}^{-1}\right.$ body weight, Haematologic Technologies, Essex Junction, VT, USA) or respective vehicle from $\mathrm{MOG}_{35-55}$ immunization. Furthermore, FXII inhibitor rHA-Infestin-4 (200 $\mathrm{mg} \mathrm{kg}^{-1}$ body weight; CSL Behring, Marburg, Germany) or respective vehicle were administered by daily i.v. injection starting 1 day after $\mathrm{MOG}_{35-55}$ immunization (prophylactic regimen) or 1 day after the appearance of first clinical signs (therapeutic regimen). For AT-EAE experiments ${ }^{49,50}$, WT, $F 12^{-l-}$ or $\mathrm{C} d 87^{-1-}$ donor mice were immunized as described above for active EAE experiments, but animals received a dose of $200 \mathrm{ng}$ PTx on the day of immunization and 2 days later. LN cells were isolated 12 days post immunization, and, in some cases, further separated into $\mathrm{CD}^{+}{ }^{+} \mathrm{T}$ cells as well as $\mathrm{CD} 11 \mathrm{c}^{+} \mathrm{APCs}$ as described below. $\mathrm{LN}$ cells or $\mathrm{CD} 4^{+} \mathrm{T}$ and $\mathrm{CD} 11 \mathrm{c}^{+}$cells (ratio 5:1, conditions as described in the figures) were restimulated for $72 \mathrm{~h}$ with $10 \mu \mathrm{g} \mathrm{ml}^{-1} \mathrm{MOG}_{35-55}$ peptide and $0.5 \mathrm{ng} \mathrm{ml}^{-1} \mathrm{IL}-12$ (R\&D systems, Minneapolis, MN, USA). AT of the encephalitogenic LN cells $\left(8.4 \times 10^{6}\right.$ cells per mouse) or CD4 ${ }^{+} \mathrm{T}$ and $\mathrm{CD} 11 \mathrm{c}^{+}$ cells $\left(1.5 \times 10^{7}\right.$ cells per mouse) in $200 \mu \mathrm{l}$ PBS was performed by i.p. injection into recipient mice. For the generation of BM chimera ${ }^{51}$, WT and $C d 87^{-l-}$ mice were irradiated with a single dose of $10 \mathrm{~Gy}$, and BM cells from WT or $C d 87^{-1-}$ mice from the same litter were injected i.v. into the irradiated mice $\left(4.0 \times 10^{6}\right.$ cells per mouse). Six weeks later, active EAE was induced as above described. RR-EAE was induced in $\mathrm{SJL} / \mathrm{JRj}$ mice by vaccination with $75 \mu \mathrm{g}$ of proteolipid protein peptide 139-151 (Genemed Synthesis, San Antonia, TX, USA) emulsified in complete Freund's adjuvant containing $600 \mu \mathrm{g} M$. tuberculosis ${ }^{29}$. Each mouse received subcutaneous injections of $200 \mu \mathrm{l}$ emulsion divided among four sites draining axillary and inguinal LN. PTx (400 ng) was administered i.p. on the day of immunization and 2 days later. Animals were scored as described below. rHA-Infestin-4 (200 $\mathrm{mg} \mathrm{kg}^{-1}$ body weight) or respective vehicle was administered daily i.v. after the onset of the first clinical RR-EAE attack. A relapse was defined as a sustained ( $>2$ day) increase in the clinical score by at least one full grade after the animal had improved previously by at least one full grade and had stabilized for at least 2 days. For a spontaneous model of EAE, 2D2 mice were crossed with Th mice $\left(I g H^{\mathrm{MOG}}\right)$ to generate double transgenic Devic mice $\left(T C R^{\mathrm{MOG}} \times I g H^{\mathrm{MOG}}\right)$ in our facility ${ }^{30}$. Littermates received daily i.p. injections of rHA-Infestin- $4\left(200 \mathrm{mg} \mathrm{kg}^{-1}\right.$ body weight) or vehicle for 20 consecutive days, starting at postnatal day 20 . The motor coordination was assessed using the rotarod test. For this, mice were placed on a rotarod with automatic timers and falling sensors (Harvard Apparatus MarchHugstetten, Germany) while the speed of the rod was accelerated from 4 to 40 r.p.m. within $10 \mathrm{~min}$, and the time the mice remained on the rod was recorded. For each mouse, the average time of three trials followed by 30 -min breaks was recorded daily. All animals were kept under standard conditions and had access to water and food ad libitum. The clinical course of EAE was monitored daily by two blinded investigators using the following score system: grade 0 , no abnormality; grade 1 , limp tail tip; grade 2 , limp tail; grade 3 , moderate hindlimb weakness; grade 4 , complete hindlimb weakness; grade 5 , mild paraparesis; grade 6 , paraparesis; grade 7 , heavy paraparesis or paraplegia; grade 8 , tetraparesis; grade 9 , quadriplegia or premoribund state; or grade 10, death. Animals with a score $>7$ were killed and the last score observed was included in the analysis until the end of

Figure 6 | FXII blockade protects from neuroinflammation and contact hypersensitivity. (a) Clinical scores of WT mice treated with rHA-Infestin-4 or vehicle starting on day 1 after EAE induction are shown. Representative data from two independent experiments are depicted (Supplementary Table 3). $(\mathbf{b}, \mathbf{c})$ Histological analysis of spinal cord sections of WT and rHA-Infestin-4-treated mice at $d_{\text {max }}$. Lumbar sections were stained with haematoxylin and eosin (HE) (b) to evaluate inflammatory foci or immunostained for Luxol fast blue (LFB) (c) to assess demyelination. Arrows indicate inflammation or demyelinated areas. Scale bars, $100 \mu \mathrm{m}$. (d) Cytokines produced by CD4 ${ }^{+}$T lymphocytes and DCs from WT mice treated with rHA-Infestin-4 or vehicle 10 days after immunization. Data from three independent experiments, each performed in duplicate are shown. Clinical scores of (e) MOG $_{35-5}$-immunized WT mice and (f) proteolipid protein peptide 139-151-immunized SJL/JRj mice treated with rHA-Infestin-4 or vehicle starting at the first day of neurologic symptoms (arrow; for detailed information, see Supplementary Table 4). (g) Clinical, cumulative EAE scores and (h) disease incidence of Devic mice treated with rHA-Infestin or vehicle starting at postnatal day 20. (i) The motor coordination of Devic mice was assessed using the rotarod. The time the mice remained on the rod was recorded. For each mouse, the average time of three trials followed by 30-min breaks was recorded daily. (j) Number of infiltrating CD4 ${ }^{+}$T cells within the central nervous system of Devic mice was analysed by flow cytometry at postnatal day 40 . (k) Ear swelling of WT or $F 12^{-/}$mice following induction of contact hypersensitivity. Representative data from three independent experiments are shown. Quantification of 2,4-dinitrobenzenesulfonic acid sodium salt-induced proliferation, and IFN- $\gamma$ and IL-17A production of LN cells from WT and F12- / - mice. Representative data in quadruplicate wells from two independent experiments are shown. In $\mathbf{a}-\mathbf{j}, 200 \mathrm{mg} \mathrm{kg}^{-1}$ body weight of rHA-Infestin-4 or vehicle was given once daily. In $\mathbf{a}-\mathbf{k}$, data are given as mean \pm s.e.m. ${ }^{\star} P<0.05$, ${ }^{\star \star} P<0.01,{ }^{\star \star \star} P<<0.001$ (for $\mathbf{a}, \mathbf{d}$ and $\mathbf{e}-\mathbf{k}$, non-parametric Mann-Whitney $U$-test; for $\mathbf{b}$ and $\mathbf{c}$, Student's $t$-test); NS, not significant. 
the experiment. The mean cumulative score for a treatment group was calculated as the sum of the daily scores of all animals from day 0 until the end of the experiment divided by the number of animals in the respective group.
Cell preparation. Single-cell suspensions of mouse LN (cervical, axillary, mesenterial and inguinal), spleens or BM were prepared from naive animals, or immunized animals 10 days after the induction of EAE or at the peak of disease $\mathrm{e}^{21}$.

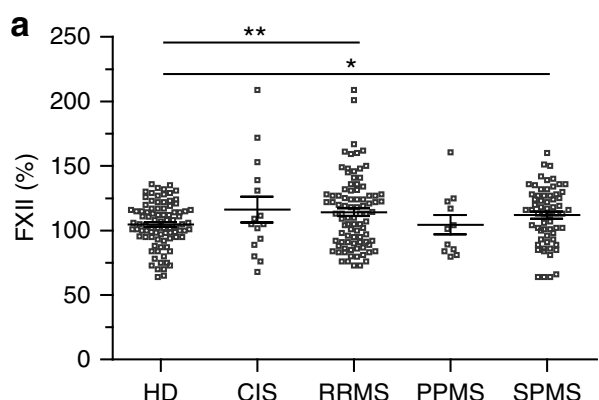

d

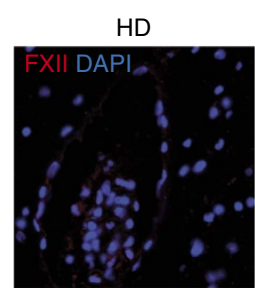

$\mathbf{f}$
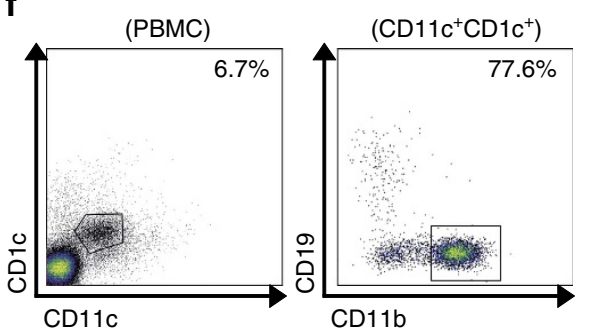

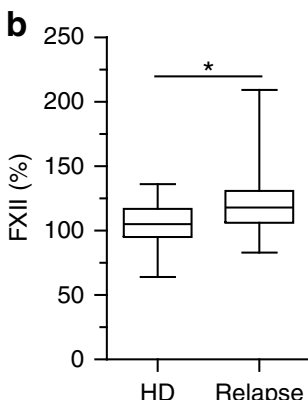

e

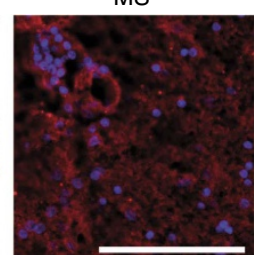

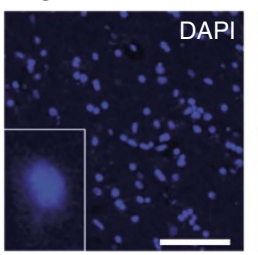
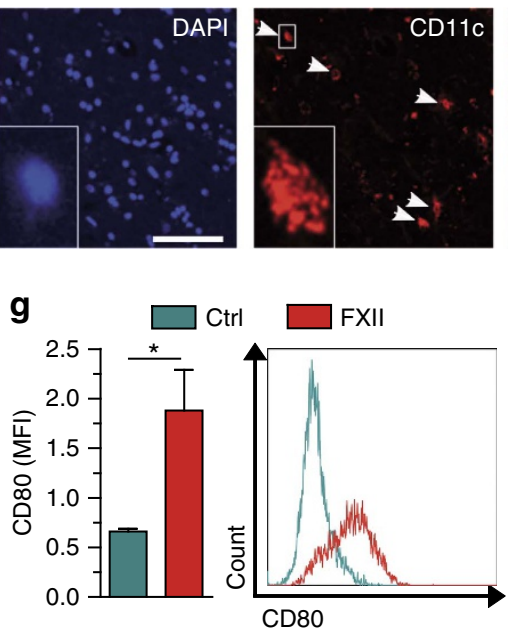

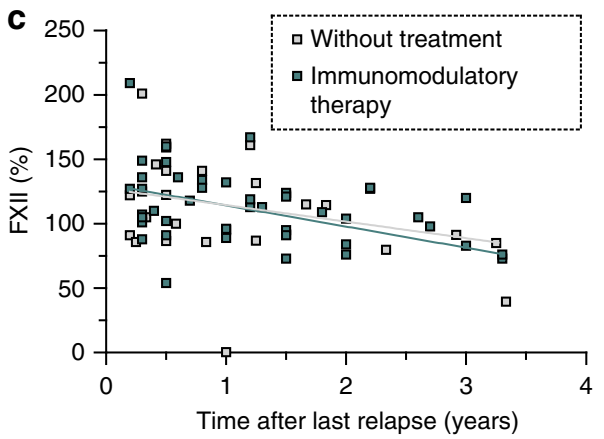

Time after last relapse (years)

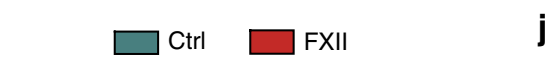

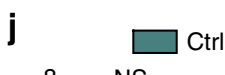
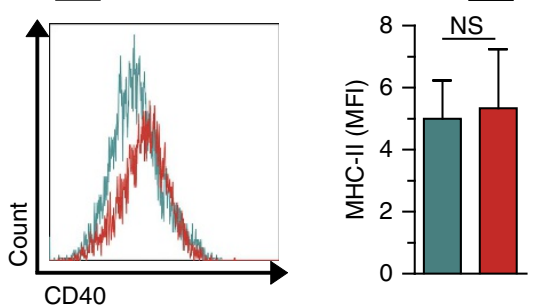
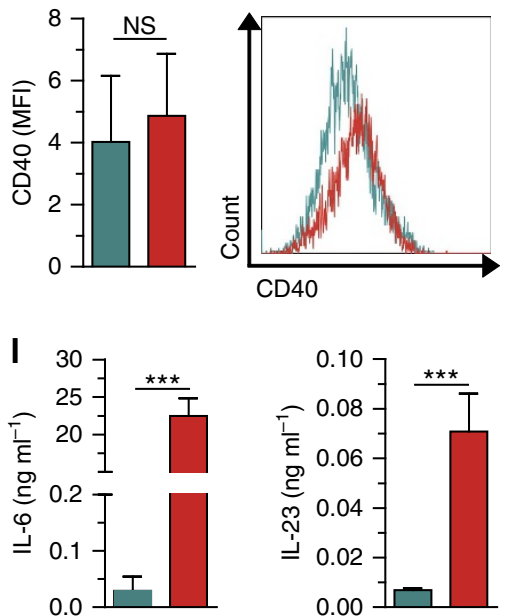

0.00
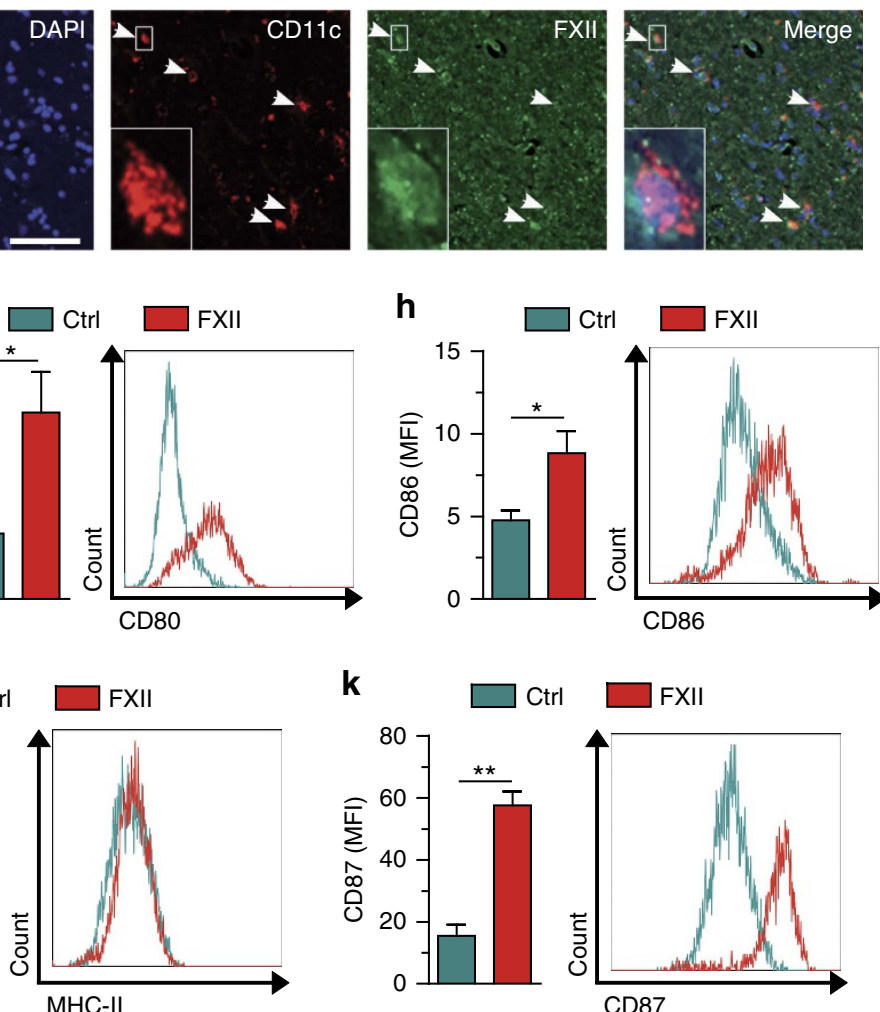

Figure 7 | Evidence for the involvement of FXII in human autoimmune CNS inflammation. (a) FXII plasma levels in individuals with clinically isolated syndrome (CIS) and MS patients (relapsing-remitting MS (RRMS), primary progressive MS (PPMS) and secondary progressive MS (SPMS)) compared with HDs. (b) FXII plasma levels in individuals with RRMS during relapse compared with HDs. (c) Correlation of FXII plasma levels with relapse-free time in individuals with RRMS. $R$ value: -0.4226 . (d) Histological analysis of CNS tissue from individuals with MS or from HDs. Sections were stained for FXII (red) and nucleus (4,6-diamidino-2-phenylindole (DAPI), blue). Scale bar, $100 \mu \mathrm{m}$. (e) Histological analysis of CNS tissue of individuals with MS. Sections were stained for CD11c (red), FXII (green) and nucleus (DAPI, blue). Scale bar, $100 \mu \mathrm{m}$. (f-k) Flow cytometric analysis of human PBMCs from HDs that were incubated with medium only (Ctrl) or stimulated with $60 \mathrm{nM} \mathrm{FXII} \mathrm{for} 24 \mathrm{~h}$. Cells were gated for CD1c ${ }^{+} \mathrm{CD} 11 \mathrm{c}+{ }^{+} \mathrm{CD} 11 \mathrm{~b}+{ }^{+} \mathrm{CD} 19^{\text {neg }}(\mathrm{cDC})$ based on indicated surface markers (shown in $\mathbf{f}$ ) and their expressions of (g) CD80, (h) CD86, (i) CD40, (j) MHC-II and (k) CD87 were determined. Representative fluorescence-activated cell sorting plots for indicated surface markers are shown. (I) Cytokine concentrations of IL-6 (left panel) and IL-23 (right panel) in the supernatants of human PBMCs treated with $60 \mathrm{nM} \mathrm{FXII} \mathrm{or} \mathrm{untreated} \mathrm{(Ctrl)} \mathrm{for} 24 \mathrm{~h}$. In $\mathbf{a , b}$ and $\mathbf{g}-\mathbf{I}$, data are given as mean \pm s.e.m. (non-parametric Mann-Whitney U-test or Student's t-test). ${ }^{\star} P<0.05,{ }^{\star \star} P<0.01,{ }^{\star \star \star} P<0.001 ; \mathrm{MFI}$, mean fluorescence intensity; NS, not significant. 
$\mathrm{CD} 4^{+} \mathrm{T}$ cells were isolated from $\mathrm{LN}$ cells of WT, $\mathrm{Fl2}^{-/-}$and $\mathrm{F} 11^{-/-}$mice using $\mathrm{CD} 4{ }^{+}$or $\mathrm{CD} 4{ }^{+} \mathrm{CD} 62 \mathrm{~L}^{+}$T-cell isolation kits (Miltenyi Biotec, Bergisch Gladbach, Germany). DCs were purified from the spleen or BM of WT, $F 12^{-1}-$ $\mathrm{Cd}_{87^{-1-}}$ and Itgam $^{-1-}$ mice using the CD11c ${ }^{+}$or pDC isolation kits (Miltenyi Biotec). All immunomagnetic cell separations were performed according to the supplier's manual. For purification of BILs $s^{52}$, brains and spinal cords from immunized WT and $F 12^{-I-}$ animals at $d_{\max }$ were collected after transcardial PBS perfusion. CNS tissues were cut into pieces and further mechanically homogenized in PBS, layered on a 30-50\% Percoll (Sigma-Aldrich) gradient and continuously centrifuged for $30 \mathrm{~min}$ at 2,500 r.p.m. Mononuclear cells were isolated at the interphase. After isolation, cells were washed and resuspended in the appropriate buffer or medium for further analysis. For quantification of cell numbers isolated from the CNS, Calibrite beads (BD) were added to freshly isolated BILs from WT and $F 12^{-1-}$ animals before washing and staining. Furthermore, human PBMCs were obtained from leukoreduction system chambers (Department of Transfusion Medicine, University of Münster) of anonymous HDs by density gradient centrifugation as described before ${ }^{53}$. Purified PBMCs were left untreated or treated with $60 \mathrm{nM}$ FXII for $24 \mathrm{~h}$ before the use for further analysis by enzyme-linked immunosorbent assay (ELISA) and flow cytometry. For rRT-PCR, CNS-derived DC subsets were isolated from the spinal cord and brain of immunized WT and $F 12^{-1-}$ animals at $d_{\max }$ by sorting on a BD fluorescence-activated cell sorting Aria III instrument after BIL purification. Cell purity was routinely $>95 \%$.

ELISA and proliferation assay. Samples of serum, plasma, single-cell suspensions of LN and CSF were taken from mice under basal conditions or at $d_{\max }$ of EAE from respective mice. CSF was collected according to the technique described by Fleming et al. ${ }^{54}$ Samples $(5 \mu \mathrm{l})$ were diluted 20 times in $50 \mathrm{mM}$ Tris-HCl buffer, $\mathrm{pH} 7.4$, containing $100 \mathrm{mM} \mathrm{NaCl}$ and $0.05 \%$ Tween-20, and frozen at $-80^{\circ} \mathrm{C}$. Determination of FXII was performed using the ELISA Kit for Coagulation FXII (USCN Life Science, Inc., Wuhan, China) according to the manufacturer's instructions. In one set of experiments, irradiated (35 Gy) DCs from WT or $F 12^{-1-}$ mice were pulsed with $10 \mu \mathrm{g} \mathrm{ml}^{-1} \mathrm{MOG}_{35-55}$ and used as APC co-cultured with syngeneic $\mathrm{CD} 4^{+} \mathrm{T}$ cells derived from the LN, as described before $^{52}$. Cells were cultured in $1 \mathrm{ml}$ DMEM containing $10 \mathrm{mM}$ HEPES, $25 \mu \mathrm{g} \mathrm{ml}^{-1}$ gentamicin, $50 \mu \mathrm{M}$ mercaptoethanol, $5 \%$ fetal calf serum (FCS), $2 \mathrm{mM}$ glutamine and $1 \%$ non-essential amino acids (Cambrex, Verviers, Belgium) for 2 days and stimulated with $10 \mu \mathrm{g} \mathrm{ml}^{-1} \mathrm{MOG}_{35-55}$. $\left[{ }^{3} \mathrm{H}\right]$ thymidine (Amerham, Piscataway, NJ, USA) was added for the final $14 \mathrm{~h}$, and radioactivity was measured on a $\beta$-scintillation counter (TopCount NXT, PerkinElmer, Rodgau-Jügesheim, Germany). The supernatants were analysed for different cytokines by ELISA. Fractioned DC subpopulations were incubated for $48 \mathrm{~h}$ with medium alone, $1 \mu \mathrm{g} \mathrm{ml}^{-1}$ LPS (for cDCs) or $10 \mu \mathrm{g} \mathrm{ml}^{-1} \mathrm{CpG}$ oligodeoxynucleotide 1,826 (for pDCs) in the absence or presence of FXII, non-cleavable FXII (CSL Behring) or FXIIa (American Diagnostica Inc.-now Sekisui Diagnostics, Stamford, CT, USA). Cytokine production from BILs was measured in culture supernatants collected after a 24 -h cell incubation with $10 \mu \mathrm{g} \mathrm{ml}^{-1} \mathrm{MOG}_{35-55}$. Mouse cytokines (IL-6, IL10 , IL-12, IL-17A, IL-23, IL-27, IFN- $\gamma$ and the active form of TGF- $\beta 1$ ) and human cytokines (IL-6 and IL-23) were assessed in culture supernatants of the abovedescribed cells by ELISA using specific kits (R\&D Systems, Peprotech, Hamburg, Germany, and eBioscience, San Diego, CA, USA) according to the manufacturer's instructions. The concentrations of CAMP in CDCs were measured using cAMP XP assay kit (Cell Signaling Technology, Cambridge, UK). Briefly, cDCs were incubated with medium only or with $1 \mu \mathrm{g} \mathrm{ml}^{-1}$ LPS for $10 \mathrm{~min}$ in the absence or presence of FXII. Reactions were stopped by aspirating the medium, and then the cells were lysed with $100 \mu \mathrm{l}$ of lysis buffer. Cell lysate was transferred into microtiter plates, and cAMP concentrations were measured according to the manufacturer's protocol. BK levels were determined using the Bradykinin ELISA Kit (Phoenix Pharmaceuticals, Inc., Karlsruhe, Germany) with minor modifications. Briefly, biotin-labelled antigen was diluted 20 times to increase the sensitivity. The competitive immunoextraction step was carried out by incubating for $4 \mathrm{~h}$ at room temperature (RT) under agitation. Peptides were detectable at a $1-10 \mathrm{pg} \mathrm{ml}^{-1}$ linear range with $0.1 \mathrm{pg} \mathrm{ml}^{-1}$ minimum detectable concentration ${ }^{42}$. For complement ( $\mathrm{C} 5 \mathrm{a}$ ) detection, plates were precoated with a rat anti-mouse $\mathrm{C} 5 \mathrm{a}$ capture antibody (clone I52-1486; BD) diluted in coating buffer $\left(100 \mu \mathrm{M} \mathrm{NaHCO}_{3}\right.$ and $34 \mu \mathrm{M} \mathrm{Na}_{2} \mathrm{CO}_{3}, \mathrm{pH} 9.5$ ), and incubated overnight ${ }^{55}$. This capture antibody is specific for a neoepitope exposed only in mouse C5a/C5adesArg, and does not cross react with native $\mathrm{C} 5$. Then, plates were blocked for $1 \mathrm{~h}$ in assay diluent (10\% FCS/PBS, followed by a 2 -h incubation with samples and standards. Thereafter, a rat anti-mouse C5a biotin-labelled detection antibody (clone I52-278; $\mathrm{BD}$ ) was added for $1 \mathrm{~h}$. To detect captured mouse C5a, streptavidin-horseradish peroxidase (BD) was added for $30 \mathrm{~min}$, followed by tetramethylbenzidine (Sigma-Aldrich); the reaction was stopped using $1 \mathrm{M} \mathrm{H}_{2} \mathrm{SO}_{4}$, and the plate was read at $450 \mathrm{~nm}$. Concentrations of measured analytes were calculated via four-parameter logistic curve fitting according to standard curves, respectively. For in vitro cell treatments, FXII, non-cleavable FXII and FXIIa were diluted in medium to a final concentration of $60 \mathrm{nM}$, unless otherwise specified.

Histology and immunohistochemistry/-cytochemistry. For murine CNS tissue, spinal cords were removed after transcardial perfusion with PBS from naive WT mice or from $\mathrm{MOG}_{35-55^{-}}$-immunized WT, $F 11^{-1-}$ and $F 12^{-1-}$ mice at $d_{\max }$ embedded in Tissue-Tek optimum cutting temperature (OCT) compound (Miles Laboratories, Elkhart, IN, USA), and cut into 10- $\mu \mathrm{m}$-thin sections from the lumbar region. For human CNS tissue, human autopsy and biopsy material from MS patients and HDs was obtained from The UK Multiple Sclerosis Tissue Bank (Division of Neuroscience and Mental Health, London, UK, $n=5$ ). For the present study, five MS cases were analysed for whom cryofixed brain tissue was available. The lesions fulfilled the morphologic criteria of an inflammatory demyelinating process consistent with MS when stained with haematoxylin and eosin (HE), Luxol fast blue (LFB)-periodic acid Schiff myelin stain and Bielschowsky's silver impregnation for axons. Cryofixed tissues from MS patients and HDs were cut into $10-\mu \mathrm{m}$ sections. For immunohistochemistry/-cytochemistry, sections or cell cultures were postfixed with $4 \%$ paraformaldehyde for $10 \mathrm{~min}$ at RT, washed with $10 \mathrm{mM}$ PBS, blocked for $1 \mathrm{~h}$ at RT with $1 \times$ PBS containing $5 \%$ bovine serum albumin (BSA), $1 \%$ normal goat serum and 0.3\% Triton X-100 (Sigma), and incubated with primary antibody at $4{ }^{\circ} \mathrm{C}$ overnight. Primary antibodies were diluted in $1 \times$ PBS containing 5\% BSA and $1 \%$ normal goat serum, and incubated overnight at $4{ }^{\circ} \mathrm{C}$. Sections were stained with the primary antibodies to the following: FXII (1:50, Proteintech), human CD11c (1:100, clone 3.9, Abcam, Cambridge, UK), human albumin (1:50, Origene Technologies, Rockville, MD, USA), ionized calcium-binding adapter molecule 1 (1:250, polyclonal, Wako Chemicals $\mathrm{GmbH}$, Neuss, Germany), glial fibrillary acidic protein (GFAP; 1:1,000, clone G-A5, Sigma-Aldrich) and mouse CD11c (1:1,000, clone N418, eBioscience, San Diego, CA, USA). Astrocyte and microglia cultures were stained with anti-GFAP and antiCD11b (1:1,000, clone EPR1344, Abcam), respectively. In addition, both were stained with anti-MHC-I (1:200, clone ER-HR52, Abcam) and anti-MHC-II (1:50, clone NIMR-4, Abcam). After washing steps, secondary antibodies were diluted in $1 \times$ PBS containing $1 \%$ BSA and incubated for $1 \mathrm{~h}$ at RT. The following secondary antibodies were used: Alexa Fluor 488-coupled goat anti-mouse (1:100, polyclonal, Invitrogen, Waltham, MA USA) or goat anti-Armenian hamster ( $1: 100$, polyclonal, Invitrogen), and Cy3-coupled goat anti-rabbit or anti-mouse (1:800, polyclonal, Dianova, Hamburg, Germany). All stainings were embedded in peqGOLD (Peqlab, Erlangen, Germany) before microscopic analysis. Negative controls were obtained by either omitting the primary or secondary antibody and revealed no detectable signal (not shown). To reveal inflammatory infiltrates and demyelination ${ }^{21}$, sections were stained with HE and LFB according to the standard procedures. All stainings were examined by microscopy (Axiophot2, Zeiss, Oberkochen, Germany) with a charge-coupled device camera (Zeiss, Oberkochen, Germany) and analysed in a blinded manner using Axiovision (Zeiss) and also Image J software. For quantification, inflammatory foci (HE), demyelinated areas (LFB) and the fluorescence intensity of ionized calcium-binding adapter molecule 1 and GFAP were counted on three slices of six mice per group, and the fluorescence intensity of MHC-I and MHC-II per area was calculated for five coverslips per condition, whereas the value of each coverslip is the mean of five cells per coverslip.

Flow cytometry. For the detection of cell surface markers and intracellular/ intranuclear markers by flow-activated cell-sorting analysis, single-cell suspensions from murine LN, spleen and BIL of WT and $F 12^{-I-}$ mice under basal conditions, or 10 days after the induction of EAE or at the peak of disease, as well as fractioned cell populations and human PBMCs were stained for $30 \mathrm{~min}$ at $4{ }^{\circ} \mathrm{C}$, with appropriate combination of indicated fluorescence-labelled monoclonal antibodies in PBS containing $0.1 \% \mathrm{NaN}_{3}$ and $0.1 \% \mathrm{BSA}$. Corresponding isotype controls were used for all stainings. For blocking of $\mathrm{Fc}$ receptors, cells were preincubated with purified anti-CD16/CD32 antibody (BioLegend, London, UK, $1.0 \mu \mathrm{g}$ per $10^{6}$ cells in $100 \mu \mathrm{l}$ volume) or with human Fc receptor-blocking reagent (Miltenyi Biotec, Bergisch Gladbach, Germany) for $5 \mathrm{~min}$ on ice before immunostaining. The following monoclonal antibodies were used at 1:200 dilutions for the detection of cell surface markers: CD3 (clone 17A2, BioLegend), CD4 (clone RM4-5, BioLegend), CD8a (clone 53-6.7, BioLegend), CD11b (clone M1/70, eBioscience), CD11c (clone N418, BioLegend), CD25 (clone PC61, BioLegend), CD40 (clone 1C10, eBioscience), CD45R/B220 (clone RA3-6B2, BD), CD80 (clone 16-10A1, $\mathrm{BD}$ ), CD86 (clone GL1, BD), CD154 (also known as CD40L, clone MR1, BioLegend), CD317 (clone 927, BioLegend), Ly-6C (clone HK1.4, BioLegend), MHC-II (clone M5/114.15.2, eBioscience) and TCR- $\gamma / \delta$ (clone GL3, BioLegend) for mouse cells; and CD1c (clone AD5-8E7, Miltenyi Biotec), CD11b (clone M1/70, BioLegend), CD11c (clone 3.9, eBioscience), CD19 (clone HIB19, BD), CD40 (clone 5C3, BioLegend), CD80 (clone L307.4, BD), CD86 (clone 2331, BD), CD87 (clone VIM5, eBioscience) and MHC-II (clone G46-6, BD) for human cells. The biotinylated polyclonal anti-mouse CD87 antibody (1:20, R\&D Systems) was detected by a following fluorescence-labelled streptavidin-conjugated antibody (1:100, Invitrogen). For immunofluorescent staining of intracellular cytokines, peripheral LN cells as well as CNS infiltrates were isolated 10 days after the induction of EAE or at the peak of disease and polyclonally restimulated for $4 \mathrm{~h}$ at $37^{\circ} \mathrm{C}$ in the presence of phorbol 12 -myristate 13-acetate/ionomycin and brefeldin A, using Leukocyte Activation Cocktail (BD) to block cytokine secretion. In the case of in vitro $\mathrm{T}_{\mathrm{H}} 1$ and $\mathrm{T}_{\mathrm{H}} 17$ differentiation (which is described below), cells were treated with brefeldin A (BD) for $8 \mathrm{~h}$ after culturing. After cell-specific surface staining, mouse IL-17A (1:50, clone eBio17B7, eBioscience) or IFN- $\gamma$ (1:50, clone $\mathrm{XMG1.2,} \mathrm{BD}$ ) protein expression was evaluated by intracellular staining using the Cytofix/Cytoperm Plus Kit (BD) according to the manufacturer's protocol. For intranuclear Foxp3 (1:100, clone FJK-16S, eBioscience) analyses, after cell-specific 
surface staining, cells were fixed/permeabilized with the Foxp3/Transcription Factor Staining Buffer Set (eBioscience) according to the manufacturer's protocol. Stained cells were assayed on a FACSGallios flow cytometer using Kaluza software (Beckman Coulter, Krefeld, Germany).

rRT-PCR. RNA isolation and RT-PCR were performed as previously described following TaqMan gene expression assays (Applied Biosystems, Foster City, CA, USA $)^{21}$ : Tbx21 (Mm00450960_m1), Gata3 (Mm00484683_m1), Rorc (Mm01261622_m1), Foxp3 (Mm00475162_m1), Brdkb1 (B1R, Mm00432059_s1), Brdkb2 (B2R, Mm00437788_s1), Cd87 (Mm00440911_m1), Par1

(Mm00438851_m1), Par2 (Mm00433160_m1), Par3 (Mm00473929_m1), Par4 (Mm01228147_m1), Il-6 (Mm00446190_m1) and eukaryotic 18S ribosomal RNA (Hs99999901_s1). Results were analysed using the StepOne software (Applied Biosystems) and the comparative Ct (Threshold cycle) method. Data are expressed as $2^{-\Delta \Delta \mathrm{Ct}}$ for the experimental gene of interest normalized to the housekeeping gene and presented as fold change relative to control.

Western blot. Spinal cord was homogenized in radioimmunoprecipitation assay buffer ( $25 \mathrm{mM}$ Tris (pH 7.4), $150 \mathrm{mM} \mathrm{NaCl}, 1 \% \mathrm{NP}-40)$ containing $0.1 \%$ SDS and $4 \%$ proteinase inhibitor (complete protease inhibitor cocktail (Roche, Basel, Swiss $))^{19,55}$. Samples were sonified for $10 \mathrm{~s}$. Afterwards, tissue lysates were centrifuged at $15,000 \mathrm{~g}$ for $30 \mathrm{~min}$ at $4^{\circ} \mathrm{C}$, and the supernatants were used for bicinchoninic acid protein assay and subsequent western blot analysis. The total lysates were treated with $4 \times$ SDS-PAGE loading buffer (final concentration: $62.5 \mathrm{mM}$ Tris (pH 6.8), $3 \% \beta$-mercaptoethanol, $8 \% \mathrm{SDS}, 15 \%$ glycerol) at $95^{\circ} \mathrm{C}$ for $5 \mathrm{~min}$. A $20-\mu \mathrm{g}$ amount of total protein was electrophoresed and transferred to a polyvinylidene difluoride membrane. After blocking for 30 min with blocking buffer (5\% non-fat dry milk, $50 \mathrm{mM}$ Tris- $\mathrm{HCl} \mathrm{pH} 7.5,0.05 \%$ Tween-20), membranes were incubated with anti-fibrin/fibrinogen polyclonal antibody 1:500 (cross-reactive for fibrin and fibrinogen; Acris Antibodies, Herford, Germany). After a washing step with TBST (50 mM Tris-HCl (pH 7.5), 0.05\% Tween-20), membranes were incubated for $1 \mathrm{~h}$ with horseradish peroxidase-conjugated donkey anti-rabbit immunoglobulin G (for fibrin/fibrinogen; Dianova) at a dilution of 1:5,000 and were finally developed using ECL plus (GE Healthcare, Hamburg, Germany). Images have been cropped for presentation. Full-size images are presented in Supplementary Fig. 10.

MBMECs and transmigration assays. MBMECs ${ }^{21}$ were prepared from brains of WT and $\mathrm{Blr}^{-1-}$ mice, and cultured 6 days before reseeding on Collagen IV/fibronectin- (Sigma) coated Transwell inserts with $3.0 \mu \mathrm{m}$ pore polyester membrane (Corning, Lowell, MA, USA). Purity, confluency and cell morphology were checked on a regular basis by flow cytometry, resistance measurements and microscopy. To induce upregulation of B1R, MBMECs were inflamed in vitro using IFN- $\gamma$ and TNF- $\alpha$ (each $500 \mathrm{IU} \mathrm{ml}^{-1}$, Peprotech) for $24 \mathrm{~h}$. Naive LN cells from WT and $F 12^{-1-}$ mice were loaded in the upper chamber and were allowed to migrate towards 5\% FCS. After an incubation period of $18 \mathrm{~h}$, migrated cells from the lower chamber of two compartments were collected, and the relative cell number of $\mathrm{CD} 4^{+} \mathrm{T}$ cells was determined by flow cytometry. To assess the effects of FXII on MBMECs, the cells were treated with FXII $(60 \mathrm{nM})$ under naive or inflamed conditions with IFN- $\gamma$ and TNF- $\alpha$ (each $500 \mathrm{IU} \mathrm{ml}^{-1}$ ) for $24 \mathrm{~h}$ during which the transendothelial resistance was monitored with the cellZscope apparatus (nanoAnalytics $\mathrm{GmbH}$, Münster, Germany). Twenty-four hours post inflammation, MBMEC supernatants were collected, and the concentration of proinflammatory chemokines was assessed using the LEGENDplex Mouse Proinflammatory Chemokine immunoassay (catalogue no. 740007; BioLegend) according to the manufacturer's instructions. To assess MBMEC permeability, $24 \mathrm{~h}$ post inflammation with or without FXII, naive splenocytes from WT mice were loaded on the upper chamber of the transwell and were allowed to migrate for $18 \mathrm{~h}$ towards 5\% FCS. For quantification of migrated cells, Calibrite beads were added before collecting the cells from the lower chamber. Numbers of migrated cells were determined by counting $1.0 \times 10^{4}$ references beads by flow cytometry as described before ${ }^{56}$.

In vitro cell differentiation. Purified naive $\mathrm{CD} 4{ }^{+} \mathrm{CD} 62 \mathrm{~L}^{+} \mathrm{T}$ cells were activated for 3 days with $5 \mu \mathrm{g} \mathrm{ml}^{-1}$ of plate-bound CD3-specific (clone 145-2C11; eBioscience) and $1 \mu \mathrm{g} \mathrm{ml}^{-1}$ soluble CD28-specific (clone $37.51 ; \mathrm{BD}$ ) antibodies in the absence or presence of $60 \mathrm{nM}$ FXII, and in the presence of various combinations of recombinant cytokines and blocking antibodies as follows: $10 \mu \mathrm{g} \mathrm{ml}^{-1}$ anti-IL-4 (clone 11B11, eBioscience) and $10 \mathrm{ng} \mathrm{ml}^{-1} \mathrm{IL}-12$ (Peprotech) for $\mathrm{T}_{\mathrm{H}} 1$ cells; $5 \mathrm{ng} \mathrm{ml}^{-1}$ human TGF- $\beta$ (R\&D Systems), $20 \mathrm{ng} \mathrm{ml}^{-1}$ IL-6 (eBioscience), $10 \mu \mathrm{gl}^{-1}$ anti-IFN- $\gamma$ (clone XMG1.2, eBioscience) and $10 \mu \mathrm{g} \mathrm{ml}^{-1}$ anti-IL-4 for $\mathrm{T}_{\mathrm{H}} 17$ cells; $5 \mathrm{ng} \mathrm{ml}^{-1}$ TGF- $\beta, 10 \mu \mathrm{g} \mathrm{ml}^{-1}$ anti-IFN- $\gamma$ and $10 \mu \mathrm{g} \mathrm{ml}^{-1}$ anti-IL-4 for iTreg cells. After 3 days at $37^{\circ} \mathrm{C}$ and $5 \% \mathrm{CO}_{2}$, cells of $\mathrm{T}_{\mathrm{H}} 1$ and $\mathrm{T}_{\mathrm{H}} 17$ differentiation were further analysed by flow cytometry as described above.

Contact hypersensitivity. We sensitized female mice by applying $25 \mu \mathrm{l}$ of $1 \%$ $(\mathrm{w} / \mathrm{v})$ dinitrofluorobenzene in acetone/olive oil $(4: 1, \mathrm{v} / \mathrm{v})$ on the shaved abdominal skin. After 5 days, animals were rechallenged by applying $20 \mu \mathrm{l}$ of $0.3 \%$ dinitrofluorobenzene to the left ear. To determine ear swelling, ear thickness was measured with a micrometre before and $24 \mathrm{~h}$ after antigen re-exposure. $\mathrm{LN}$ cells from WT and $\mathrm{F}^{-1-}$ mice were prepared and cultured on day 5 .

Primary murine cell cultures. For microglia culture, pups of WT mice were decapitated at postnatal days 1-5 and, after removal of the cerebellum, the meninges were removed. Up to five brains were mechanically homogenized together in $5 \mathrm{ml} \mathrm{L-glutamine-containing} \mathrm{DMEM} \mathrm{supplemented} \mathrm{with} 10 \%$ heatinactivated FCS, $1 \%$ non-essential amino acids and $1 \%$ penicillin/streptomycin with a 5 -ml pipette. The supernatants were incubated for $5 \mathrm{~min}$ on ice, and after centrifugation of the pooled supernatants at $486 \mathrm{~g}$ for $5 \mathrm{~min}$ at RT, the pellets were resuspended in $1 \mathrm{ml}$ medium/2-3 brains. The cell suspensions were transferred to poly-L-lysin-precoated $75-\mathrm{cm}^{2}$ cell culture flasks in a total volume of $10 \mathrm{ml}$ each and incubated at $37^{\circ} \mathrm{C}$ and $5 \% \mathrm{CO}_{2}$. After 1 and 7 days of culturing, the medium was changed. After 7 additional days of culturing, microglial cells were selectively detached by carefully knocking against the flask. Suspended microglia cells were pelleted at $300 \mathrm{~g}$ for $5 \mathrm{~min}$ at RT, before 60,000 cells in $250 \mu \mathrm{l}$ medium were seeded for further analysis. For immunocytochemistry and rRT-PCR experiments, cells were seeded on poly-L-lysin-precoated coverslips and cytokine production in the supernatants was assessed by ELISA as described above after treating the cells. Therefore, cells were incubated for $24 \mathrm{~h}$ at $37^{\circ} \mathrm{C}$ and $5 \% \mathrm{CO}_{2}$ after seeding to rest, and stimulated with LPS $\left(1 \mu \mathrm{g} \mathrm{ml}^{-1}\right)$ or LPS $\left(1 \mu \mathrm{g} \mathrm{ml}^{-1}\right)$ and FXII $(60 \mathrm{nM})$, or not stimulated for 1 additional day. Astrocyte cell cultures were obtained from WT mice on postnatal days $1-3$ as described ${ }^{51}$. In brief, mice were killed by decapitation, their brains were transferred to Hanks' Balanced Salt Solution and the meninges were removed. After preparation of the cortex, tissue was collected in $13.5 \mathrm{ml}$ Hanks' Balanced Salt Solution and incubated for $15 \mathrm{~min}$ at $37^{\circ} \mathrm{C}$ with $1.5 \mathrm{ml}$ DNAse I and $1.5 \mathrm{ml}$ trypsin $2.5 \%$. Cells were mechanically dissociated and filtered through a $45-\mu \mathrm{m}$ cell strainer. Then, $4.5 \times 10^{6}$ astrocytes were cultured in $75-\mathrm{cm}^{2}$ flasks in astrocytes medium $(1 \times$ minimum essential medium, $1 \mathrm{mM}$ sodium pyruvate, $33.3 \mathrm{mM}$ glucose, $10 \%$ horse serum and $1 \%$ penicillin/streptomycin). The medium was changed $24 \mathrm{~h}$ later and twice per week thereafter. When reaching a confluent layer, astrocytes were trypsinized with $0.25 \%$ trypsin and EDTA, and frozen in freezing medium (astrocyte medium and 10\% dimethyl sulfoxide). Cells were defrosted and cultured on poly-D-lysine-coated coverslips for 2 weeks in astrocyte medium at $37^{\circ} \mathrm{C}$ and $5 \% \mathrm{CO}_{2}$ for further analysis as described for microglia.

Patients. Fresh blood samples were obtained from 260 MS patients referred to the Departments of Neurology at the University Hospital Würzburg and the University of Münster. MS diagnosis was made according to the revised criteria of McDonald et $a l . .^{57}$ Of the patients included in the study, 87 had not received immunomodulatory treatment except for corticosteroids, with the last dose administered at least 3 months before study entry. In addition, we included 173 patients who had received different immunomodulatory therapies (glatiramer acetate, interferons, fingolimod, natalizumab, teriflunomide and mitoxantrone). All patients gave informed consent in accordance with the Declaration of Helsinki and a protocol approved by the Ethics Committees of the Universities of Würzburg and Münster. Blood $(10-20 \mathrm{ml})$ was collected by venous puncture using a tourniquet. In parallel, 130 sex- and age-matched HDs were included in the study. FXII activity of plasma samples was determined with an automated blood coagulation system (Siemens Healthcare, Eschborn, Germany) according to the manufacturer's instructions. The percentage of FXII activity was calculated in comparison with standard human plasma and FXII-deficient plasma (Siemens Healthcare, Eschborn, Germany).

Statistical methods. EAE data were analysed by the non-parametric Mann-Whitney $U$-test. To compare the mean day of onset and maximal score, the Mann-Whitney rank-sum test was used. Paired data were evaluated by the Student's $t$-test. Mann-Whitney $U$-test for parametric data without normality data sets was used. In the case of multiple comparisons, one-way analysis of variance (ANOVA) followed by post hoc analysis using Tukey's multiple comparisons test or Kruskal-Wallis test with Dunn post hoc analysis was used. Data were analysed using Prism 5.04 (Graph Pad, USA), and the values of probability $(P)<0.05$ were considered as statistically significant. The level of significance was labelled as NS (not significant), ${ }^{*} P<0.05,{ }^{*} P<0.01$ or ${ }^{* *} P<0.001$. In vitro and in vivo data are expressed as mean \pm s.e.m.)from at least three independent experiments, unless otherwise indicated. The number of animals $(n=12)$ necessary to detect a standardized effect size on EAE score $\geq 0.5$ (WT mice versus $F 12^{-I^{-}}$mice) was calculated via a priori sample size analysis with the following assumptions: $\alpha=0.05, \beta=0.2$ (power $80 \%$ ), mean and s.d. $20 \%$ of the mean (StatMate 2.0 ; Prism 5.03, Graph Pad). To compare FXII activity in patients, analysis of variance was used.

Data availability. The authors declare that the data supporting the findings of the study are available within the article and its Supplementary Information. 


\section{References}

1. Ganguly, D., Haak, S., Sisirak, V. \& Reizis, B. The role of dendritic cells in autoimmunity. Nat. Rev. Immunol. 13, 566-577 (2013).

2. Bhat, R. \& Steinman, L. Innate and adaptive autoimmunity directed to the central nervous system. Neuron 64, 123-132 (2009).

3. Steinman, L. A brief history of $\mathrm{T}(\mathrm{H}) 17$, the first major revision in the $\mathrm{T}(\mathrm{H}) 1 / \mathrm{T}(\mathrm{H}) 2$ hypothesis of $\mathrm{T}$ cell-mediated tissue damage. Nat. Med. 13, 139-145 (2007)

4. Korn, T., Bettelli, E., Oukka, M. \& IL-17, Kuchroo VK. and Th17 Cells. Annu. Rev. Immunol. 27, 485-517 (2009).

5. Steinman, L. A rush to judgment on Th17. J. Exp. Med. 205, 1517-1522 (2008).

6. $\mathrm{Wu}, \mathrm{H}$. Y. et al. In vivo induction of Tr1 cells via mucosal dendritic cells and AHR signaling. PLoS ONE 6, e23618 (2011).

7. Quintana, F. J. et al. Control of $\mathrm{T}(\mathrm{reg})$ and $\mathrm{T}(\mathrm{H}) 17$ cell differentiation by the aryl hydrocarbon receptor. Nature 453, 65-71 (2008).

8. Lock, C. et al. Gene-microarray analysis of multiple sclerosis lesions yields new targets validated in autoimmune encephalomyelitis. Nat. Med. 8, 500-508 (2002)

9. Tzartos, J. S. et al. Interleukin-17 production in central nervous systeminfiltrating T cells and glial cells is associated with active disease in multiple sclerosis. Am. J. Pathol. 172, 146-155 (2008).

10. Langer, H. F. et al. Platelets contribute to the pathogenesis of experimental autoimmune encephalomyelitis. Circ. Res. 110, 1202-1210 (2012).

11. Gveric, D., Herrera, B., Petzold, A., Lawrence, D. A. \& Cuzner, M. L. Impaired fibrinolysis in multiple sclerosis: a role for tissue plasminogen activator inhibitors. Brain 126, 1590-1598 (2003).

12. Adams, R. A. et al. The fibrin-derived gamma377-395 peptide inhibits microglia activation and suppresses relapsing paralysis in central nervous system autoimmune disease. J. Exp. Med. 204, 571-582 (2007).

13. Ryu, J. K. et al. Blood coagulation protein fibrinogen promotes autoimmunity and demyelination via chemokine release and antigen presentation. Nat. Commun. 6, 8164 (2015).

14. Han, M. H. et al. Proteomic analysis of active multiple sclerosis lesions reveals therapeutic targets. Nature 451, 1076-1081 (2008).

15. Schmaier, A. H. The elusive physiologic role of Factor XII. J. Clin. Invest. 118, 3006-3009 (2008).

16. Renne, T., Schmaier, A. H., Nickel, K. F., Blomback, M. \& Maas, C. In vivo roles of factor XII. Blood 120, 4296-4303 (2012).

17. Schmaier, A. H. Assembly, activation, and physiologic influence of the plasma kallikrein/kinin system. Int. Immunopharmacol. 8, 161-165 (2008).

18. LaRusch, G. A. et al. Factor XII stimulates ERK1/2 and Akt through uPAR, integrins, and the EGFR to initiate angiogenesis. Blood 115, 5111-5120 (2010).

19. Kleinschnitz, C. et al. Targeting coagulation factor XII provides protection from pathological thrombosis in cerebral ischemia without interfering with hemostasis. J. Exp. Med. 203, 513-518 (2006).

20. Maas, C. \& Renne, T. Regulatory mechanisms of the plasma contact system. Thromb. Res. 129(Suppl 2): S73-S76 (2012).

21. Gobel, K. et al. Blockade of the kinin receptor B1 protects from autoimmune CNS disease by reducing leukocyte trafficking. J. Autoimmun. 36, 106-114 (2011)

22. Strainic, M. G., Shevach, E. M., An, F., Lin, F. \& Medof, M. E. Absence of signaling into $\mathrm{CD} 4(+)$ cells via $\mathrm{C} 3 \mathrm{aR}$ and $\mathrm{C} 5 \mathrm{aR}$ enables autoinductive TGF-betal signaling and induction of Foxp $3(+)$ regulatory T cells. Nat. Immunol. 14, 162-171 (2012).

23. Cirino, G. \& Severino, B. Thrombin receptors and their antagonists: an update on the patent literature. Expert Opin. Ther. Pat. 20, 875-884 (2010).

24. Simon, D. I. et al. Identification of a urokinase receptor-integrin interaction site. Promiscuous regulator of integrin function. J. Biol. Chem. 275, 10228-10234 (2000)

25. Zhang, H., Colman, R. W. \& Sheng, N. Regulation of CD11b/CD18 (Mac-1) adhesion to fibrinogen by urokinase receptor (uPAR). Inflamm. Res. 52, 86-93 (2003)

26. Li, K. et al. Cyclic AMP plays a critical role in C3a-receptor-mediated regulation of dendritic cells in antigen uptake and T-cell stimulation. Blood 112, 5084-5094 (2008).

27. Schnurr, M. et al. Extracellular nucleotide signaling by P2 receptors inhibits IL-12 and enhances IL-23 expression in human dendritic cells: a novel role for the cAMP pathway. Blood 105, 1582-1589 (2005).

28. Hagedorn, I. et al. Factor XIIa inhibitor recombinant human albumin Infestin- 4 abolishes occlusive arterial thrombus formation without affecting bleeding. Circulation 121, 1510-1517 (2010).

29. Fallarino, F. et al. Metabotropic glutamate receptor-4 modulates adaptive immunity and restrains neuroinflammation. Nat. Med. 16, 897-902.

30. Bittner, S. et al. Effects of glatiramer acetate in a spontaneous model of autoimmune neuroinflammation. Am. J. Pathol. 184, 2056-2065 (2014).

31. Krishnamoorthy, G., Lassmann, H., Wekerle, H. \& Holz, A. Spontaneous opticospinal encephalomyelitis in a double-transgenic mouse model of autoimmune T cell/B cell cooperation. J. Clin. Invest. 116, 2385-2392 (2006).
32. Bouma, G. \& Strober, W. The immunological and genetic basis of inflammatory bowel disease. Nat. Rev. Immunol. 3, 521-533 (2003).

33. Lowes, M. A., Bowcock, A. M. \& Krueger, J. G. Pathogenesis and therapy of psoriasis. Nature 445, 866-873 (2007).

34. Adams, R. A., Schachtrup, C., Davalos, D., Tsigelny, I. \& Akassoglou, K. Fibrinogen signal transduction as a mediator and therapeutic target in inflammation: lessons from multiple sclerosis. Curr. Med. Chem. 14, 2925-2936 (2007).

35. Reitamo, S., Reunala, T., Konttinen, Y. T., Saksela, O. \& Salo, O. P. Inflammatory cells, IgA, C3, fibrin and fibronectin in skin lesions in dermatitis herpetiformis. Br. J. Dermatol. 105, 167-177 (1981).

36. Davalos, D. et al. Fibrinogen-induced perivascular microglial clustering is required for the development of axonal damage in neuroinflammation. Nat. Commun. 3, 1227 (2012)

37. Akassoglou, K. et al. Fibrin depletion decreases inflammation and delays the onset of demyelination in a tumor necrosis factor transgenic mouse model for multiple sclerosis. Proc. Natl Acad. Sci. USA 101, 6698-6703 (2004).

38. Albert-Weissenberger, C., Siren, A. L. \& Kleinschnitz, C. Ischemic stroke and traumatic brain injury: the role of the kallikrein-kinin system. Prog. Neurobiol. 101-102, 65-82 (2013).

39. Prat, A. et al. Kinin B1 receptor expression and function on human brain endothelial cells. J. Neuropathol. Exp. Neurol. 59, 896-906 (2000).

40. Prat, A. et al. Kinin B1 receptor expression on multiple sclerosis mononuclear cells: correlation with magnetic resonance imaging T2-weighted lesion volume and clinical disability. Arch. Neurol. 62, 795-800 (2005).

41. Prat, A. et al. Bradykinin B1 receptor expression and function on T lymphocytes in active multiple sclerosis. Neurology 53, 2087-2092 (1999).

42. Schulze-Topphoff, U. et al. Activation of kinin receptor B1 limits encephalitogenic T lymphocyte recruitment to the central nervous system. Nat Med. 15, 788-793 (2009)

43. Segal, B. M. Th17 cells in autoimmune demyelinating disease. Semin. Immunopathol. 32, 71-77.

44. Grohmann, U. et al. Functional plasticity of dendritic cell subsets as mediated by CD40 versus B7 activation. J. Immunol. 171, 2581-2587 (2003).

45. Banchereau, J. \& Steinman, R. M. Dendritic cells and the control of immunity Nature 392, 245-252 (1998).

46. Kraft, P., De Meyer, S. F. \& Kleinschnitz, C. Next-generation antithrombotics in ischemic stroke: preclinical perspective on 'bleeding-free antithrombosis'. J. Cereb. Blood Flow Metab. 32, 1831-1840 (2012).

47. Mitroulis, I. et al. Developmental endothelial locus-1 attenuates complementdependent phagocytosis through inhibition of Mac-1-integrin. Thromb. Haemost. 111, 1004-1006 (2014).

48. Gyetko, M. R., Sud, S. \& Chensue, S. W. Urokinase-deficient mice fail to generate a type 2 immune response following schistosomal antigen challenge. Infect. Immun. 72, 461-467 (2004)

49. Cravens, P. D. et al. Lymph node-derived donor encephalitogenic CD4 ${ }^{+}$ $\mathrm{T}$ cells in C57BL/6 mice adoptive transfer experimental autoimmune encephalomyelitis highly express GM-CSF and T-bet. J. Neuroinflammation 8, 73 (2011).

50. Breuer, J. et al. Ultraviolet B light attenuates the systemic immune response in central nervous system autoimmunity. Ann. Neurol. 75, 739-758 (2014).

51. Bittner, S. et al. Endothelial TWIK-related potassium channel-1 (TREK1) regulates immune-cell trafficking into the CNS. Nat. Med. 19, 1161-1165 (2013).

52. Ortler, S. et al. B7-H1 restricts neuroantigen-specific $\mathrm{T}$ cell responses and confines inflammatory CNS damage: implications for the lesion pathogenesis of multiple sclerosis. Eur. J. Immunol. 38, 1734-1744 (2008)

53. Pankratz, S. et al. Human $\mathrm{CD} 4{ }^{+} \mathrm{HLA}-\mathrm{G}^{+}$regulatory $\mathrm{T}$ cells are potent suppressors of graft-versus-host disease in vivo. FASEB J. 28, 3435-3445 (2014).

54. Fleming, J. O., Ting, J. Y., Stohlman, S. A. \& Weiner, L. P. Improvements in obtaining and characterizing mouse cerebrospinal fluid. Application to mouse hepatitis virus-induced encephalomyelitis. J. Neuroimmunol. 4, 129-140 (1983).

55. Langhauser, F. et al. Kininogen deficiency protects from ischemic neurodegeneration in mice by reducing thrombosis, blood-brain barrier damage, and inflammation. Blood 120, 4082-4092 (2012).

56. Ruck, T. et al. $\mathrm{CD} 4{ }^{+} \mathrm{NKG} 2 \mathrm{D}^{+} \mathrm{T}$ cells exhibit enhanced migratory and encephalitogenic properties in neuroinflammation. PloS ONE 8, e81455 (2013).

57. Polman, C. H. et al. Diagnostic criteria for multiple sclerosis: 2010 revisions to the McDonald criteria. Ann. Neurol. 69, 292-302 (2011).

\section{Acknowledgements}

We would like to thank C. Butz and J. Budde for excellent technical assistance. We also thank Dr Weimer (CSL Behring $\mathrm{GmbH}$ ) for providing rHA-Infestin-4 and the non-cleavable FXII. This work was supported by the Deutsche Forschungsgemeinschaft, DFG (GO 2505/1-1 to K.G., ME3283/5-1 and ME3283/6-1 to S.G.M, KFO274 to H.F.L.), EKFS (2015_A113 to K.G.), Medical Faculty Münster (Junior Research Group to K.G.), SFB 688 (TP A13 to C.K.), SFB (TRR 128/1 2012 TP B06 to S.G.M.), IMF (GÖ 11140 
to K.G.), CIM (to S.G.M.), Volkswagen Foundation (Lichtenberg Program to H.F.L.), Biogen Idec GmbH, 85737 Ismaning, Germany (unrestricted grant to analyse the role of blood coagulation in EAE to C.K.) and Novartis Pharma GmbH, 90429 Nürnberg, Germany (unrestricted grant to analyse the role of blood coagulation in EAE to C.K.)

\section{Author contributions}

K.G., S.G.M. and C.K. conceived the study and designed the experiments. K.G. and S.P. performed the main experimental work and analysed the data. C.-M.A., F.L., S.B., T.R., A.M.H., M.M., P.K., T.K., S.G., J.B., M.H., D.S., D.B., A.K.-P., S.K., I.M., M.K.S. and C.C.G. performed additional experiments. C.R. provided Cd87-deficient mice and supervised these experiments. M.W.N. and C.P. synthesized and provided rHA-Infestin-4. K.G. interpreted the data and drafted the manuscript, and S.P., M.W.N., L.K., B.K., T.K., H.F.L., T.P., B.N., H.W., C.K., T.C. and S.G.M interpreted the data and extensively revised the manuscript. H.W., C.K. and S.G.M. funded the study. All authors provided substantial input throughout the process.

\section{Additional information}

Supplementary Information accompanies this paper at http://www.nature.com/ naturecommunications
Competing financial interests: M.W.N. is an employee of CSL Behring GmbH and owns employee shares in CSL Limited. C.P. is an employee of CSL Limited and owns employee shares in CSL Limited. K.G., M.W.N., C.K. and S.G.M. hold a patent to trea neuroinflammatory disorders with FXIIa inhibitors. The remaining authors declare no competing financial interests.

Reprints and permission information is available online at http://npg.nature.com/ reprintsandpermissions/

How to cite this article: Göbel, K. et al. Blood coagulation factor XII drives adaptive immunity during neuroinflammation via CD87-mediated modulation of dendritic cells. Nat. Commun. 7:11626 doi: 10.1038/ncomms11626 (2016).

(c) (i) This work is licensed under a Creative Commons Attribution 4.0 International License. The images or other third party material in this article are included in the article's Creative Commons license, unless indicated otherwise in the credit line; if the material is not included under the Creative Commons license, users will need to obtain permission from the license holder to reproduce the material. To view a copy of this license, visit http://creativecommons.org/licenses/by/4.0/ 